\title{
Haar Wavelet Method for Nonlinear Vibration of Functionally Graded CNT-Reinforced Composite Beams Resting on Nonlinear Elastic Foundations in Thermal Environment
}

\author{
Jianyu Fan $(D)$ and Jin Huang $(D)$ \\ Key Laboratory of Electronic Equipment Structure Design, Ministry of Education, Xidian University, Xi'an 710071, China \\ Correspondence should be addressed to Jianyu Fan; xdfjy1990@126.com and Jin Huang; jhuang@mail.xidian.edu.cn
}

Received 13 June 2018; Accepted 26 August 2018; Published 3 October 2018

Academic Editor: Matteo Strozzi

Copyright (c) 2018 Jianyu Fan and Jin Huang. This is an open access article distributed under the Creative Commons Attribution License, which permits unrestricted use, distribution, and reproduction in any medium, provided the original work is properly cited.

\begin{abstract}
This paper presents a simple and effective approach based on the Haar wavelet discretization method (HWDM) for the nonlinear vibration analysis of carbon nanotube-reinforced composite (CNTRC) beams resting on a nonlinear elastic foundation in a thermal environment. Material properties are assumed to be functionally graded (FG) in the thickness direction and temperature-dependent and are evaluated through the extended rule of mixture. Based on the first-order shear deformation beam theory in conjunction with the von Kármán nonlinearity, the nonlinear governing equations of CNTRC beams on nonlinear elastic foundations are derived as well as the related boundary conditions. Moreover, the initial thermal stress due to uniform temperature rise is considered in this study. To evaluate the nonlinear natural frequencies, the obtained equations are discretized into a set of nonlinear algebraic equations through HWDM and then the direct iteration technique is employed to solve the resulting algebraic equations. The convergence and comparison studies are carried out, and the results indicate that the numerical rate of convergence of the proposed method is in agreement with the convergence theorem, and good accuracy of the present results is observed. Studies on the effects of different parameters such as CNT volume fraction, distribution type of CNTs, foundation stiffness coefficients, boundary condition, slenderness ratio, temperature rise, and initial thermal stress on the linear frequencies and the nonlinear frequency ratios are also reported. This study offers an insight into the vibration behaviors of CNTRC beams resting on nonlinear elastic foundation subjected to the uniform temperature rise.
\end{abstract}

\section{Introduction}

Owing to their extraordinary mechanical, thermal, and electrical properties, carbon nanotubes (CNTs) have been considered to be an ideal reinforcement material for high performance composites. Structural applications of carbon nanotubereinforced composites (CNTRCs) may include aviation, automotive, military, and space-related parts, in which the material with high strength, stiffness, and light weight is required. In the past decades, extensive numerical and experimental studies have focused on the mechanical properties of CNTRCs. An analytical study on axial Young's modulus of single-walled CNT arrays with diameters ranging from nanometer to meter scales was conducted by Sun et al. [1]. Their results showed that the mechanical properties of CNTs outperform those of carbon fibers. Gojny et al. [2] presented the effects of different types of CNT fillers on mechanical properties of epoxy-based nanocomposites. They found that the strength and stiffness of the resulting CNT/epoxy composite can be remarkably enhanced. Omidi et al. [3] showed that only a $3 \mathrm{wt} . \%$ addition of multiwalled CNTs increases Young's modulus and the tensile strength of epoxy-based composites up to $43.1 \%$ and $55.2 \%$, respectively. The above researches have proved that the addition of CNTs into the matrix leads to significant improvements in the strength and stiffness of the composite.

Functionally graded materials (FGMs) are a class of novel materials with properties that vary spatially according to a given nonuniform distribution of the reinforcement phase. Inspired by the concept of FGMs, Shen [4] first proposed CNT-based FGMs, namely, functionally graded carbon nanotube-reinforced composites (FG-CNTRCs). In his study, CNTs were distributed linearly along the plate's thickness directions into an isotropic matrix and the results showed that the nonlinear bending behavior of CNTRC plates 
can be considerably improved through the FG distribution of CNTs. Recently, using a powder metallurgy route, Kwon et al. [5] successfully fabricated functionally graded CNT-reinforced aluminum matrix composites, which proved the feasibility of the concept of FG-CNTRCs. After the pioneering work of Shen, extensive investigations about FG-CNTRC beams, plates, and shells were carried out to explore their mechanical properties, such as static bending behaviors [6], elastic buckling and postbuckling characteristics [7-10], and linear and nonlinear free vibration features [11-14]. For more details, a comprehensive review on the mechanical analysis of FG-CNTRC structures has been presented by Liew et al. [15].

Composite beams are extensively used in many engineering applications where higher strength to weight ratio is desired, such as aircraft structures and space vehicles. In recent years, researches on the mechanical properties of FG-CNTRC beams have been increasing rapidly. Ke et al. studied the nonlinear free nonlinear [16] and dynamic stability [17] of FGCNTRC beams and found that the natural and excitation frequencies of FG-CNTRC beams with symmetrical distribution of CNTs are higher than those of beams with uniform or unsymmetrical distribution of CNTs. Wu et al. investigated extensively nonlinear vibration [18], mechanical, and thermal postbuckling $[19,20]$ behaviors of FG-CNTRC beams with various geometric imperfections. Their results indicated that geometric imperfections have a considerable effect on the mechanical behaviors of the FG-CNTRC beams. Ansari et al. [21] examined nonlinear forced vibration behaviors of FGCNTRC Timoshenko beams using the GDQM and pseudoarc length technique. Beams resting on an elastic foundation often come across in engineering practice. So far, some studies have been conducted on the mechanical behaviors of FG-CNTRC beams on the elastic foundation. Using a two-step perturbation technique, Shen and Xiang [22] dealt with the linear and nonlinear free vibration, nonlinear bending, thermal buckling, and thermal postbuckling of simply supported FG-CNTRC beams resting on a linear elastic foundation. Free vibrations and buckling of FG-CNTRC beams resting on the linear elastic foundation were carried out by Yas and Samadi [23] using the generalized differential quadrature method (GDQM). Their results found that both the natural frequency and the critical buckling load increase with the use of an elastic foundation.

From the above literature review, it is noted that the aforementioned researches only considered the mechanical behaviors of FG-CNTRC beams resting on linear elastic foundations. However, with the increase in the applied external load, the beam's transverse deflection will influence the axial force and the resulting governing equations become coupled and nonlinear. In this case, the linear elastic subgrade model is inadequate to describe the real behavior of the foundation and hence the use of a more sophisticated nonlinear one becomes inevitable. However, to the best knowledge of the authors, no research has examined the mechanical behaviors of FGCNTRC beams interacting with nonlinear elastic foundations. Moreover, composite structures made of FGMs are often operated in a thermal environment and the initial thermal stresses due to the temperature change will occur, which tends to affect the mechanical behaviors of structures [24]. However, from the aforementioned studies, only the temperature dependence of material properties was considered and the influence of initial thermal stresses was neglected.

Wavelet methods have been developed as a new powerful tool for mathematical analysis and engineering computation in recent years. Different types of wavelets have been employed in numerical approximations, such as Chebyshev [25], Legendre [26], Daubechies [27], and Haar wavelets [28]. Among them, the Haar wavelet has gained extensive attention due to its unique properties such as simple applicability, orthogonality, and compact support. Hence, Haar wavelet methods have been widely applied for solving differential, integral, and integrodifferential equations [28-32]. Moreover, the Haar wavelet discretization method (HWDM) introduced in Ref. [34] was adopted successfully for analysis of wide class of solid mechanics problems. For instance, free vibration of composite laminated cylindrical, conical, and annular plate structures was studied by Xie et al. by means of the HWDM $[33,34]$. Hein and Feklistova [35] utilized the HWDM to analyze vibration behaviors of axially FG beams with various boundary conditions. Majak et al. [36] investigated the accuracy issues of the HWDM for solving the transverse vibration problem of the FG beam, and they found that the numerical order of convergence of the HWDM is equal to two and is in good agreement with the theoretical value. Recently, Majak et al. developed a new higher order Haar wavelet method (HOHWM) for FGM structures, and their results showed that using the proposed method allows to improve the order of convergence of the HWDM from two to four and to reduce the absolute error by several orders of magnitude [37]. It can be seen from the aforementioned literature review that most of researches on the application of the Haar wavelet approach for the analysis of composite structures are concerned with linear problems, such as free vibration. However, lots of scientific problems in solid mechanics problems are inherently nonlinear. Hence, study on the use of the Haar wavelet method to the nonlinear problem in composite mechanics is extremely necessary.

In the present work, an attempt is made to employ the Haar wavelet method to analyze the nonlinear vibration behavior of FG-CNTRC beams in a thermal environment. The considered beam is fixed on a three-parameter nonlinear elastic foundation with cubic nonlinearity and a shearing layer and meanwhile subjected to a uniform temperature rise. The temperature-dependent material properties and the initial thermal stress due to the uniform temperature rise are both taken into consideration. Based on the first-order shear deformation theory (FSDT) in conjunction with the von Kármán nonlinearity, the nonlinear governing equations of CNTRC beams are derived via Hamilton's principle. The resultant governing equations and corresponding boundary conditions are first discretized into nonlinear algebraic equations using the HWDW and then solved by a direct iteration technique to obtain the linear and nonlinear frequencies of FG-CNTRC beams. To validate the convergence and accuracy of the proposed method, some numerical examples are conducted to compare the results obtained from the proposed method with those available in the open literature. A detailed parametric study is carried out to examine the effects of the CNT volume fraction, distribution type of CNTs, foundation stiffness coefficients, boundary condition, and slenderness ratio on the 
nonlinear vibration behavior of FG-CNTRC beams. Moreover, the influences of the temperature and initial thermal stress are also investigated.

\section{Theoretical Formulations}

2.1. System Description. Consider an FG-CNTRC beam resting on a three-parameter nonlinear elastic foundation with cubic nonlinearity and a shearing layer, as shown in Figure 1. The geometric sizes of the beam are the length $L$ and the thickness $H$. The reference surface of the nanocomposite beam is taken to be at its midplane where an orthogonal coordinate system $(x, z)$ with the origin at one end of the beam is fixed and the $x$ - and $z$-axes are taken along the length and thickness directions, respectively. The nonlinear elastic foundation is assumed to be made up of massless springs with shear interaction among the beam and them, and no part of the beam lifts off the foundation during its large amplitude vibration. The load-displacement relationship of the mechanical model of the foundation considered here is given as [38]

$$
F_{0}=k_{\mathrm{L}} w+k_{\mathrm{NL}} w^{3}-k_{\mathrm{S}} \frac{\partial^{2} w}{\partial x^{2}},
$$

where $F_{0}$ denotes the reaction force of the nonlinear elastic foundation; $k_{\mathrm{L}}\left(\mathrm{N} / \mathrm{m}^{3}\right)$ and $k_{\mathrm{NL}}(\mathrm{N} / \mathrm{m})$ indicate linear and nonlinear coefficients of the Winkler elastic foundation, respectively; $k_{\mathrm{S}}(\mathrm{N} / \mathrm{m})$ represents the coefficient of the shear stiffness of the elastic foundation; and $w$ is the displacement component in the $z$ direction.

The CNTRC beam adopted here is assumed to be made of a mixture of uniaxially aligned SWCNTs and isotropic matrices. The CNTs are distributed into the matrix material in a functionally graded (FG) or uniform form along the beam thickness direction. In this study, two types of FG distributions are considered, FG-X and FG-O. Meanwhile, as a counterpart, the uniform distribution (UD) is also treated. Various CNT distribution types in the composite are depicted graphically in Figure 2, and the volume fraction of CNTs $V_{\mathrm{CNT}}$ for each distribution pattern can be expressed as [23]

$$
\begin{gathered}
\mathrm{UD}: V_{\mathrm{CNT}}=V_{\mathrm{CNT}}^{*}, \\
\text { FG-X: } V_{\mathrm{CNT}}=2 V_{\mathrm{CNT}}^{*}\left(2 \frac{|z|}{H}\right), \\
\text { FG-O }: V_{\mathrm{CNT}}=2 V_{\mathrm{CNT}}^{*}\left(1-2 \frac{|z|}{H}\right),
\end{gathered}
$$

where $V_{\mathrm{CNT}}^{*}$ denotes the total CNT volume fraction given by

$$
V_{\mathrm{CNT}}^{*}=\frac{w_{\mathrm{CNT}}}{w_{\mathrm{CNT}}+\left(\rho^{\mathrm{CNT}} / \rho^{\mathrm{m}}\right)-\left(\rho^{\mathrm{CNT}} / \rho^{\mathrm{m}}\right) w_{\mathrm{CNT}}},
$$

where $w_{\mathrm{CNT}}$ denotes the mass fraction, $\rho^{\mathrm{CNT}}$ and $\rho^{\mathrm{m}}$ represent the mass densities of the CNT and matrix, respectively. It should be noted that the total mass fractions in FG-X, FG-O, and UD CNTRC beams are the same.

The effective material properties of CNTRCs vary continuously in the beam thickness direction and are calculated using the extended rule of mixtures as [4]

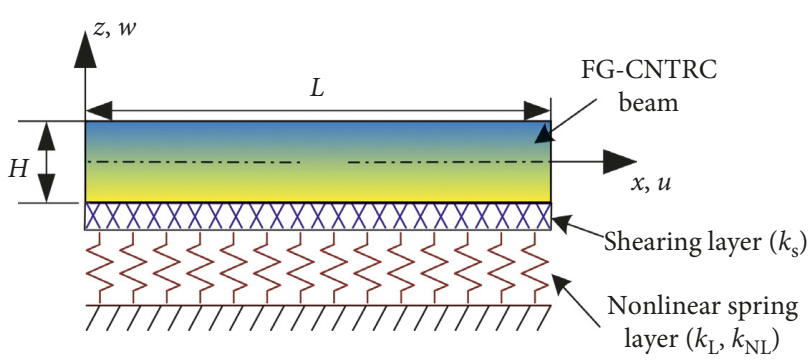

FIgURE 1: Geometry and notations of the FG-CNTRC beam interacting with nonlinear elastic foundations.

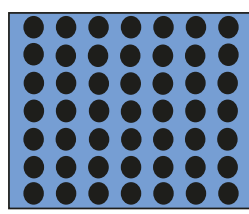

(a)

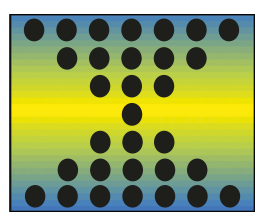

(b)

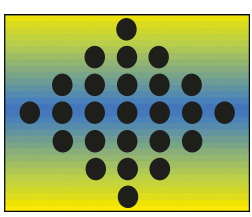

(c)
FIgURe 2: Different CNT distribution types in the CNTRC composite structure: (a) UD, (b) FG-X, and (c) FG-O.

$$
\begin{aligned}
& E_{11}=\eta_{1} V_{\mathrm{CNT}} E_{11}^{\mathrm{CNT}}+V_{\mathrm{m}} E^{\mathrm{m}}, \\
& \frac{\eta_{2}}{E_{22}}=\frac{V_{\mathrm{CNT}}}{E_{22}^{\mathrm{CNT}}}+\frac{V_{\mathrm{m}}}{E^{\mathrm{m}}}, \\
& \frac{\eta_{3}}{G_{12}}=\frac{V_{\mathrm{CNT}}}{G_{12}^{\mathrm{CNT}}}+\frac{V_{\mathrm{m}}}{G^{\mathrm{m}}},
\end{aligned}
$$

where $E_{11}^{\mathrm{CNT}}, E_{22}^{\mathrm{CNT}}$, and $G_{12}^{\mathrm{CNT}}$ are Young's modulus and shear modulus of SWCNTs, respectively, and $E^{\mathrm{m}}$ and $G^{\mathrm{m}}$ indicate the corresponding properties of the isotropic matrix. The coefficients $\eta_{1}, \eta_{2}$, and $\eta_{3}$ are the efficiency parameters to explain the scale-dependent material properties and are evaluated by matching the effective properties of CNTRC obtained from the MD simulations with those from the rule of mixtures [39]. Moreover, in Equation (4), $V_{\mathrm{CNT}}$ and $V_{\mathrm{m}}$ indicate the volume fractions of CNTs and matrix phases, respectively, which satisfy the condition $V_{\mathrm{CNT}}+V_{\mathrm{m}}=1$. It can be seen from Equation (4) that the effective material properties of CNTRC beams are position dependent.

The mass density, effective Poisson's ratio, and thermal expansion coefficient of the CNTRC composite can also be obtained according to the rule of mixtures as follows [22]:

$$
\begin{aligned}
\rho & =V_{\mathrm{CNT}} \rho^{\mathrm{CNT}}+V_{\mathrm{m}} \rho^{\mathrm{m}}, \\
v_{12} & =V_{\mathrm{CNT}} v_{12}^{\mathrm{CNT}}+V_{\mathrm{m}} v^{\mathrm{m}}, \\
\alpha_{11} & =\frac{V_{\mathrm{CNT}} E_{11}^{\mathrm{CNT}} \alpha_{11}^{\mathrm{CNT}}+V_{\mathrm{m}} E^{\mathrm{m}} \alpha^{\mathrm{m}}}{V_{\mathrm{CNT}} E_{11}^{\mathrm{CNT}}+V_{\mathrm{m}} E^{\mathrm{m}}},
\end{aligned}
$$

in which $v_{12}^{\mathrm{CNT}}$ and $v^{\mathrm{m}}$ are the Poisson ratios of SWCNTs and the matrix, respectively, and $\alpha_{11}^{\mathrm{CNT}}$ and $\alpha^{\mathrm{m}}$ denote the corresponding thermal expansion coefficients. 
2.2. Governing Relations and Equations. Based on the firstorder shear deformation beam theory, the displacement field of a CNTRC beam is expressed as

$$
\begin{aligned}
& u_{x}=u(x, t)+z \phi(x, t), \\
& u_{z}=w(x, t),
\end{aligned}
$$

where $\left(u_{x}, u_{z}\right)$ indicate the displacement components of an arbitrary point $(x, z)$ in the beam; $(u, w)$ denote the displacement components of the point on the midplane; $\phi$ denotes the rotation of the beam cross section; and $t$ is the time. The von Kármán-type nonlinear strain-displacement relationships associated with the thermal effect can be written as [40]

$$
\begin{aligned}
& \varepsilon_{x x}=\frac{\partial u}{\partial x}+z \frac{\partial \phi}{\partial x}+\frac{1}{2}\left(\frac{\partial w}{\partial x}\right)^{2}-\alpha_{11} \Delta T, \\
& \gamma_{x z}=\frac{\partial w}{\partial x}+\phi,
\end{aligned}
$$

where $\Delta T$ is the temperature change with respect to a reference temperature. It is assumed that the considered beam is initially stress-free at the reference temperature $T_{0}$ and then subjected to a uniform temperature rise $\Delta T=T-T_{0}$, where $T$ is the current temperature.

The force and moment resultants of the CNTRC beam based on the linear constitutive relationship are given by [40]

$$
\begin{aligned}
N_{x} & =A_{11} \frac{\partial u}{\partial x}+B_{11} \frac{\partial \phi}{\partial x}+\frac{1}{2} A_{11}\left(\frac{\partial w}{\partial x}\right)^{2}-N_{x}^{\mathrm{T}}, \\
M_{x} & =B_{11} \frac{\partial u}{\partial x}+D_{11} \frac{\partial \phi}{\partial x}+\frac{1}{2} B_{11}\left(\frac{\partial w}{\partial x}\right)^{2}-M_{x}^{\mathrm{T}}, \\
Q_{x z} & =\kappa A_{55}\left(\frac{\partial w}{\partial x}+\phi\right),
\end{aligned}
$$

where $N_{x}, M_{x}$, and $Q_{x z}$ are the axial force, bending moment, and shear force, respectively. Here, $\kappa$ is the shear correction factor and is taken as $\kappa=5 / 6$ in this study. The stiffness components are defined as

$$
\begin{aligned}
\left\{A_{11}, B_{11}, D_{11}\right\} & =\int_{-H / 2}^{H / 2} Q_{11}(z, T)\left\{1, z, z^{2}\right\} d z, \\
A_{55} & =\int_{-H / 2}^{H / 2} Q_{55}(z, T) d z,
\end{aligned}
$$

where $\quad Q_{11}(z, T)=E_{11}(z, T) /\left[1-v_{12}(z) v_{21}(z)\right] \quad$ and $\mathrm{Q}_{55}(z, T)=G_{12}(z, T)$. Here, $N_{x}^{\mathrm{T}}$ and $M_{x}^{\mathrm{T}}$ are the thermal force and moment resultants,

$$
\left\{N_{x}^{\mathrm{T}}, M_{x}^{T}\right\}=\int_{-H / 2}^{H / 2} Q_{11}(z, T) \alpha_{11}(z, T)\{1, z\} d z .
$$

By means of Hamilton's principle, the governing differential equations of a FG-CNTRC beam resting on a nonlinear elastic foundation in a thermal environment can be derived as follows $[20,23]$ :

$$
\begin{gathered}
\frac{\partial N_{x}}{\partial x}=I_{0} \frac{\partial^{2} u}{\partial t^{2}}+I_{1} \frac{\partial^{2} \phi}{\partial t^{2}} \\
\frac{\partial Q_{x z}}{\partial x}+\frac{\partial}{\partial x}\left(N_{x} \frac{\partial w}{\partial x}\right)-k_{\mathrm{L}} w-k_{\mathrm{NL}} w^{3} \\
+k_{g} \frac{\partial^{2} w}{\partial x^{2}}=I_{0} \frac{\partial^{2} w}{\partial t^{2}}, \\
\frac{\partial M_{x}}{\partial x}-Q_{x z}=I_{1} \frac{\partial^{2} u}{\partial t^{2}}+I_{2} \frac{\partial^{2} \phi}{\partial t^{2}},
\end{gathered}
$$
where $\left\{I_{0}, I_{1}, I_{2}\right\}=\int_{-H / 2}^{H / 2} \rho(z)\left\{1, z, z^{2}\right\} d z$ are the inertia
terms.

Substituting Equations (8)-(10) into Equation (11), the nonlinear governing equations of the considered beam in terms of displacements can be obtained as

$$
\begin{aligned}
A_{11} \frac{\partial^{2} u}{\partial x^{2}}+B_{11} \frac{\partial^{2} \phi}{\partial x^{2}}+A_{11} \frac{\partial w}{\partial x} \frac{\partial^{2} w}{\partial x^{2}}=I_{0} \frac{\partial^{2} u}{\partial t^{2}}+I_{1} \frac{\partial^{2} \phi}{\partial t^{2}} \\
\kappa A_{55}\left(\frac{\partial^{2} w}{\partial x^{2}}+\frac{\partial \phi}{\partial x}\right)+A_{11}\left(\frac{\partial^{2} u}{\partial x^{2}} \frac{\partial w}{\partial x}+\frac{\partial u}{\partial x} \frac{\partial^{2} w}{\partial x^{2}}\right) \\
+B_{11}\left(\frac{\partial^{2} \phi}{\partial x^{2}} \frac{\partial w}{\partial x}+\frac{\partial \phi}{\partial x} \frac{\partial^{2} w}{\partial x^{2}}\right) \\
+\frac{3}{2} A_{11}\left(\frac{\partial w}{\partial x}\right)^{2} \frac{\partial^{2} w}{\partial x^{2}}-N_{x}^{T} \frac{\partial^{2} w}{\partial x^{2}} \\
-k_{L} w-k_{N L} w^{3} \\
+k_{g} \frac{\partial^{2} w}{\partial x^{2}}=I_{0} \frac{\partial^{2} w}{\partial t^{2}} \\
B_{11} \frac{\partial^{2} u}{\partial x^{2}}+D_{11} \frac{\partial^{2} \phi}{\partial x^{2}}+B_{11} \frac{\partial w}{\partial x} \frac{\partial^{2} w}{\partial x^{2}}-\kappa A_{55}\left(\frac{\partial w}{\partial x}+\phi\right) \\
=I_{1} \frac{\partial^{2} u}{\partial t^{2}}+I_{2} \frac{\partial^{2} \phi}{\partial t^{2}} .
\end{aligned}
$$

In the present study, the boundary conditions at the two ends of the beam can be considered as either a clamped end or a hinged end, which are given by

$$
\text { Clamped(C)end: } u=w=\phi=0, \quad \text { at } x=0 \text { or } L,
$$

Hinged $(\mathrm{H})$ end : $u=w=M_{x}=0, \quad$ at $x=0$ or $L$.

In the harmonic vibration analysis, the displacements can be expressed as

$$
\begin{aligned}
& u(x, t)=U(x) e^{i \omega t}, \\
& w(x, t)=W(x) e^{i \omega t}, \\
& \phi(x, t)=\Phi(x) e^{i \omega t},
\end{aligned}
$$

where $\omega$ is the natural frequency and $i=\sqrt{-1} ; U(x), W(x)$, and $\Phi(x)$ denote the unknown displacement functions to be determined. Substituting Equation (14) into Equation (12) and introducing the following normalized variable $\xi=x / L$, 
we can obtain the nonlinear governing equations in terms of a single nondimensional variable $\xi$ as follows:

$$
\begin{gathered}
L_{1} \frac{d^{2} U}{d \xi^{2}}+L_{2} \frac{d^{2} \Phi}{d \xi^{2}}+G_{1} \frac{d W}{d \xi} \frac{d^{2} W}{d \xi^{2}}=-\omega^{2} I_{0} U-\omega^{2} I_{1} \Phi \\
L_{3} \frac{d^{2} W}{d \xi^{2}}+L_{4} \frac{d \Phi}{d \xi}+G_{1}\left(\frac{d^{2} U}{d \xi^{2}} \frac{d W}{d \xi}+\frac{d U}{d \xi} \frac{d^{2} W}{d \xi^{2}}\right) \\
+G_{2}\left(\frac{d^{2} \Phi}{d \xi^{2}} \frac{d W}{d \xi}+\frac{d \Phi}{d \xi} \frac{d^{2} W}{d \xi^{2}}\right)+G_{3}\left(\frac{d W}{d \xi}\right)^{2} \frac{d^{2} W}{d \xi^{2}} \\
-G_{\mathrm{T}} \Delta T \frac{d^{2} W}{d \xi^{2}}-k_{\mathrm{L}} W-k_{\mathrm{NL}} W \\
+\frac{k_{g}}{L^{2}} \frac{d^{2} W}{d \xi^{2}}=-\omega^{2} I_{0} W \\
L_{2} \frac{d^{2} U}{d \xi^{2}}+L_{5} \frac{d^{2} \Phi}{d \xi^{2}}+L_{6} \frac{d W}{d \xi}+L_{7} \Phi+G_{2} \frac{d W}{d \xi} \frac{d^{2} W}{d \xi^{2}} \\
=-\omega^{2} I_{1} U-\omega^{2} I_{2} \Phi
\end{gathered}
$$

where the $L_{i}, G_{i}$, and $G_{\mathrm{T}}$ are the constant coefficients defined in Appendix A. It should be noted that the variable $\xi$ satisfies $\xi \in[0,1]$ so that the Haar wavelet method can be directly used to solve the given equations.

\section{Solution Methodology}

In this section, a simple and effective numerical approach based on the Haar wavelet discretization method (HWDM) will be adopted to solve the nonlinear governing equations of the CNTRC beam. The HWDM is an effective approach for solving differential, integral, and integro-differential equations [28, 41] and will be used to discretize the derivatives in the governing equations and the boundary conditions.
3.1. The Haar Wavelet Functions and Their Integrals. The Haar wavelet is known as one of the simplest orthonormal wavelets with a compact support. Mathematically, the Haar wavelet family $h_{i}(\xi)$ is defined as a group of square waves in $\xi \in[0,1]$ with magnitude \pm 1 in given intervals and zero elsewhere, which is expressed as $[35,42]$

$$
h_{i}(\xi)=\left\{\begin{array}{l}
1, \xi \in\left[\xi_{1}(i), \xi_{2}(i)\right), \\
-1, \xi \in\left[\xi_{2}(i), \xi_{3}(i)\right), \\
0, \quad \text { elsewhere. }
\end{array}\right.
$$

where $\xi_{1}(i)=k / m, \xi_{2}(i)=(k+0.5) / m$, and $\xi_{3}(i)=(k+1) / m$. The integer $m=2^{j}(j=0,1, \ldots, J)$ indicates the factor of scale, where $J$ is the maximal level of resolution. The parameter $k$ denotes the translation parameter $(k=0,1, \ldots, m-1)$. The index $i$ is defined as $i=m+k+1$, and the maximal value is $i=2 M\left(M=2^{J}\right)$; the minimal value $i=2$ is reached when $m=$ 1 and $k=0$. It should be noted that case $i=1$ corresponds to the scaling function $h_{1}(\xi) \equiv 1$.

Let us assume that $f(\xi)$ is a square integrable and finite function in the interval $[0,1]$ and it can be expanded into the Haar wavelet series with infinite terms. In practice, the series need to be truncated, and only the finite terms of the Haar wavelet series are considered. Hence, the function $f(\xi)$ can be expressed as a finite-term series, that is,

$$
f(\xi)=\sum_{i=1}^{2 M} a_{i} h_{i}(\xi)
$$

where $a_{i} \quad(i=1, \ldots, 2 M)$ denote unknown wavelet coefficients.

To solve differential equations using the HWDM, the integrals of the Haar wavelet functions (16) are required which can be calculated analytically as follows [36]:

$$
\begin{aligned}
& p_{n, i}(\xi)=\frac{\xi^{n}}{n !}, \text { for } i=1, \\
& p_{n, i}(\xi)=\left\{\begin{array}{lc}
0, & \xi \leq \xi_{1}(i), \\
\frac{1}{n !}\left(\xi-\xi_{1}(i)\right)^{n}, & \xi_{1}(i)<\xi \leq \xi_{2}(i), \\
\frac{1}{n !}\left[\left(\xi-\xi_{1}(i)\right)^{n}-2\left(\xi-\xi_{2}(i)\right)^{n}\right], & \xi_{2}(i)<\xi \leq \xi_{3}(i), \\
\frac{1}{n !}\left[\left(\xi-\xi_{1}(i)\right)^{n}-2\left(\xi-\xi_{2}(i)\right)^{n}+\left(\xi-\xi_{3}(i)\right)^{n}\right], \xi>\xi_{3}(i), & \text { for } i>1,
\end{array}\right.
\end{aligned}
$$

$$
\xi_{l}=\frac{(l-0.5)}{2 M}, \quad l=1,2, \ldots, 2 M
$$

where $n$ indicates the integral order of the Haar wavelet function. In the case $n=0$, the function $h_{i}(\xi)$ will be obtained.

Let us divide the interval $[0,1]$ into $2 M$ subintervals of equal length, $\Delta \xi=1 / 2 M$; the coordinates of the collocation points are given as
Substitution of the collocation points in Equation (19) into Equations (16) and (18) leads to the Haar coefficient matrix $\mathbf{H}$ and the integral coefficient matrices $\mathbf{P}^{(n)}$ as follows: 


$$
\begin{gathered}
\mathbf{H}(i, l)=h_{i}\left(\xi_{l}\right), \\
\mathbf{P}^{(n)}(i, l)=p_{n, i}\left(\xi_{l}\right),
\end{gathered}
$$

where $\mathbf{H}$ and $\mathbf{P}^{(n)}$ are $2 M \times 2 M$ matrices and will be used to discretize the given governing equations in the next section.

3.2. Solution Procedure. Firstly, according to the HWDM [34], the highest-order derivatives of the unknown displacement functions with respect to the normalized variable $\xi$ in Eq. (15) can be expanded by the truncated Haar wavelet series. Hence, it is assumed that these functions can be expressed as

$$
\frac{d^{2}}{d \xi^{2}}\{U(\xi), W(\xi), \Phi(\xi)\}=\sum_{i=1}^{2 M}\left\{a_{i}, b_{i}, c_{i}\right\} h_{i}(\xi),
$$

where $a_{i}, b_{i}$, and $c_{i}$ are the unknown wavelet coefficients and $h_{i}(\xi)$ indicates the Haar wavelet function defined in Equation (16). Integrating Equation (21) and substituting Equation (19) leads to the following expressions:

$$
\begin{aligned}
\frac{d}{d \xi}\{U(\xi), W(\xi), \Phi(\xi)\}= & \sum_{i=1}^{2 M}\left\{a_{i}, b_{i}, c_{i}\right\} p_{1, i}(\xi) \\
& +\frac{d}{d \xi}\{U(0), W(0), \Phi(0)\}, \\
\{U(\xi), W(\xi), \Phi(\xi)\}= & \sum_{i=1}^{2 M}\left\{a_{i}, b_{i}, c_{i}\right\} p_{2, i}(\xi) \\
& +\xi \frac{d}{d \xi}\{U(0), W(0), \Phi(0)\} \\
& +\{U(0), W(0), \Phi(0)\},
\end{aligned}
$$

where $d\{U(0), W(0), \Phi(0)\} / d \xi$ and $\{U(0), W(0), \Phi(0)\}$ are the integrating constants to be determined.

The evaluation of Equations (21) and (22) at the given collocation points can be written in matrix form as

$$
\begin{aligned}
\frac{d^{2} U}{d \xi^{2}} & =\mathbf{H a}, \\
\frac{d^{2} W}{d \xi^{2}} & =\mathbf{H b}, \\
\frac{d^{2} \Phi}{d \xi^{2}} & =\mathbf{H c}, \\
\frac{d U}{d \xi} & =\mathbf{P}^{(1)} \mathbf{a}+\mathbf{Q}_{1} \mathbf{d}, \\
\frac{d W}{d \xi} & =\mathbf{P}^{(1)} \mathbf{b}+\mathbf{Q}_{1} \mathbf{e}, \\
\frac{d \Phi}{d \xi} & =\mathbf{P}^{(1)} \mathbf{c}+\mathbf{Q}_{1} \mathbf{f},
\end{aligned}
$$

$$
\begin{aligned}
U & =\mathbf{P}^{(2)} \mathbf{a}+\mathbf{Q}_{2} \mathbf{d}, \\
W & =\mathbf{P}^{(2)} \mathbf{b}+\mathbf{Q}_{2} \mathbf{e}, \\
\Phi & =\mathbf{P}^{(2)} \mathbf{c}+\mathbf{Q}_{2} \mathbf{f},
\end{aligned}
$$

where $\quad \mathbf{a}=\left[\begin{array}{llll}a_{1} & a_{2} & \cdots & a_{2 M}\end{array}\right]^{\mathrm{T}}, \quad \mathbf{b}=\left[\begin{array}{llll}b_{1} & b_{2} & \cdots & b_{2 M}\end{array}\right]^{\mathrm{T}}$, $\mathbf{c}=\left[\begin{array}{llll}c_{1} & c_{2} & \cdots & c_{2 M}\end{array}\right]^{\mathrm{T}}, \quad \mathbf{d}=\left[\begin{array}{lll}d U(0) / d \xi & U(0)\end{array}\right]^{\mathrm{T}}$, $\mathbf{e}=\left[\begin{array}{ll}d W(0) / d \xi W(0) & ]^{\mathrm{T}}, \quad \mathbf{f}=[d \Phi(0) / d \xi \Phi(0)\end{array}\right]^{\mathrm{T}}, \quad$ and $\mathbf{Q}_{1}=\left[\begin{array}{llll}1 & 1 & \cdots & 1 \\ 0 & 0 & \cdots & 0\end{array}\right]_{2 \times 2 M}^{\mathrm{T}}, \mathbf{Q}_{2}=\left[\begin{array}{cccc}\xi_{1} & \xi_{2} & \cdots & \xi_{2 M} \\ 1 & 1 & \cdots & 1\end{array}\right]^{\mathrm{T}}$.

Substituting Equation (23) into Equation (20) with some simple manipulation, the governing equations of the CNTRC beam can be converted into the following nonlinear algebraic equations which are expressed in the matrix form as

$$
\begin{gathered}
\mathbf{K}_{\mathbf{d d}}^{\mathrm{s}} \mathbf{X}_{d}+\mathbf{K}_{\mathbf{b d}}^{\mathrm{s}} \mathbf{X}_{\mathbf{b}}-\Delta T \mathbf{K}_{\mathbf{d d}}^{\mathrm{t}} \mathbf{X}_{\mathbf{d}}+\mathbf{K}_{\mathbf{d d}}^{\mathrm{g}} \mathbf{X}_{\mathbf{d}} \\
+\mathbf{K}_{\mathbf{b d}}^{\mathrm{g}} \mathbf{X}_{\mathbf{b}}=\omega^{2}\left(\mathbf{M}_{\mathbf{d d}}^{\mathrm{g}} \mathbf{X}_{\mathbf{d}}+\mathbf{M}_{\mathbf{b d}}^{\mathrm{g}} \mathbf{X}_{\mathrm{b}}\right)
\end{gathered}
$$

where $\mathbf{X}_{\mathbf{d}}=\left[\begin{array}{lll}\mathbf{a} & \mathbf{b} & \mathbf{c}\end{array}\right]^{\mathrm{T}}$ and $\mathbf{X}_{\mathbf{b}}=\left[\begin{array}{lll}\mathbf{d} & \mathbf{e} & \mathbf{f}\end{array}\right]^{\mathrm{T}}$. The matrices $\mathbf{K}_{\mathbf{d d}}^{\mathrm{s}}, \mathbf{K}_{\mathbf{b d}}^{\mathrm{s}}, \mathbf{K}_{\mathbf{d d}}^{\mathrm{t}}, \mathbf{M}_{\mathbf{d d}}^{\mathrm{g}}$, and $\mathbf{M}_{\mathbf{b d}}^{\mathrm{g}}$ are constant matrices, but $\mathbf{K}_{\mathbf{d d}}^{\mathrm{g}}$ and $\mathbf{K}_{\mathbf{b d}}^{\mathbf{g}}$ are dependent on the displacement component $W$, which are given in Appendix B.

The discretization of the boundary conditions can be carried out in the same way. For example, for a clamped beam in both ends, the boundary conditions can be expressed using HWDM as

$$
\begin{aligned}
& U(0)=\sum_{i=1}^{2 M} a_{i} p_{2, i}(0)+U(0)=0, \\
& U(1)=\sum_{i=1}^{2 M} a_{i} p_{2, i}(1)+\frac{d U(0)}{d \xi}+U(0)=0, \\
& W(0)=\sum_{i=1}^{2 M} b_{i} p_{2, i}(0)+W(0)=0 \\
& W(1)=\sum_{i=1}^{2 M} b_{i} p_{2, i}(1)+\frac{d W(0)}{d \xi}+W(0)=0, \\
& \Phi(0)=\sum_{i=1}^{2 M} c_{i} p_{2, i}(0)+\Phi(0)=0 \\
& \Phi(1)=\sum_{i=1}^{2 M} c_{i} p_{2, i}(1)+\frac{d \Phi(0)}{d \xi}+\Phi(0)=0 .
\end{aligned}
$$

Equation (25) can also be written in the matrix form as

$$
\mathbf{K}_{\mathrm{db}}^{\mathrm{s}} \mathbf{X}_{\mathbf{d}}+\mathbf{K}_{\mathrm{db}}^{\mathrm{s}} \mathbf{X}_{\mathbf{b}}+\mathbf{K}_{\mathrm{db}}^{\mathrm{g}} \mathbf{X}_{\mathbf{d}}+\mathbf{K}_{\mathrm{bb}}^{\mathrm{g}} \mathbf{X}_{\mathbf{b}}=0,
$$

where $\mathbf{K}_{\mathbf{d b}}^{\mathbf{s}}, \mathbf{K}_{\mathbf{d b}}^{\mathbf{s}}, \mathbf{K}_{\mathbf{d b}}^{\mathbf{g}}$, and $\mathbf{K}_{\mathbf{b b}}^{\mathbf{g}}$ are listed in Appendix B. It should be noted that the matrices $\mathbf{K}_{\mathbf{d b}}^{\mathbf{s}}, \mathbf{K}_{\mathbf{d b}}^{\mathbf{s}}, \mathbf{K}_{\mathbf{d b}}^{\mathbf{g}}$, and $\mathbf{K}_{\mathbf{b b}}^{\mathrm{g}}$ are varied for the different boundary conditions.

Assembling of Equations (24) and (26) leads to the global equations of the nonlinear vibration of the FG-CNTRC 
beam resting on the elastic foundation in a thermal environment, which are written as

$$
\left(\mathbf{K}^{\mathbf{s}}-\Delta T \mathbf{K}^{\mathbf{t}}+\mathbf{K}^{\mathrm{g}}(\mathbf{X})\right) \mathbf{X}-\omega^{2} \mathbf{M X}=0,
$$

where

$$
\begin{aligned}
\mathbf{X} & =\left[\begin{array}{l}
\mathbf{X}_{\mathbf{d}} \\
\mathbf{X}_{\mathbf{b}}
\end{array}\right], \\
\mathbf{K}^{\mathbf{s}} & =\left[\begin{array}{ll}
\mathbf{K}_{\mathbf{d d}}^{\mathrm{s}} & \mathbf{K}_{\mathbf{b d}}^{\mathbf{s}} \\
\mathbf{K}_{\mathbf{d b}}^{\mathrm{s}} & \mathbf{K}_{\mathbf{b b}}^{\mathrm{s}}
\end{array}\right], \\
\mathbf{K}^{\mathbf{t}} & =\left[\begin{array}{cc}
\mathbf{K}_{\mathbf{d d}}^{\mathrm{t}} & 0 \\
0 & 0
\end{array}\right], \\
\mathbf{K}^{\mathbf{g}} & =\left[\begin{array}{cc}
\mathbf{K}_{\mathbf{d d}}^{\mathrm{g}} & \mathbf{K}_{\mathbf{b d}}^{\mathrm{g}} \\
\mathbf{K}_{\mathbf{d b}}^{\mathbf{g}} & \mathbf{K}_{\mathbf{b b}}^{\mathrm{g}}
\end{array}\right], \\
\mathbf{M} & =\left[\begin{array}{cc}
\mathbf{M}_{\mathbf{d d}} & \mathbf{M}_{\mathbf{b d}} \\
0 & 0
\end{array}\right],
\end{aligned}
$$

where $\mathbf{X}$ is the unknown displacement vector. $\mathbf{K}^{\mathbf{s}}, \mathbf{K}^{\mathbf{g}}(\mathbf{X})$, $\mathbf{K}^{\mathbf{t}}$, and $\mathbf{M}$ denote the linear and nonlinear stiffness matrices, the stiffness matrix due to the uniform temperature rise, and the mass matrix, respectively. It should be noted that the coefficient matrices above are all dependent on the current temperature $T$. Moreover, it can be seen that the solution of Equation (27) is essentially a nonlinear eigenvalue problem.

An direct iterative method adopted by Mirzaei and Kiani [43] is used to solve the system of nonlinear eigenvalues in Equation (27). First, to solve this equation, the nonlinear terms $\mathbf{K}^{\mathbf{g}}(\mathbf{X})$ are set to zero and the resulting linear eigenvalue problem is solved to obtain the linear nature frequencies $\omega_{\mathrm{L}}$ and the corresponding linear eigenvectors $\mathbf{X}_{\mathrm{L}}$. Then, the linear eigenvectors are used to evaluate the nonlinear coefficient matrix $\mathbf{K}^{\mathrm{g}}(\mathbf{X})$. The eigenvalue problem is solved again to obtain the nonlinear nature frequencies $\omega_{\mathrm{NL}}$ and eigenvectors $\mathbf{X}_{\mathrm{NL}}$, and subsequently the nonlinear coefficient matrix is reevaluated using the obtained nonlinear eigenvectors $\mathbf{X}_{\mathrm{NL}}$. The iterative procedure continues until the frequency values from the two subsequent iterations " $r$ " and " $r+1$ " satisfy the prescribed convergence criteria

$$
\frac{\left|\omega_{\mathrm{NL}}^{r+1}-\omega_{\mathrm{NL}}^{r}\right|}{\omega_{\mathrm{NL}}^{r} \leq \zeta_{0}},
$$

where $\zeta_{0}$ is a small-value number and, in the present study, it is taken to be $0.01 \%$.

\section{Results and Discussion}

In this section, firstly, the convergence and accuracy of the present method are demonstrated by comparing the obtained results with those available in the open literature. Then, parametric studies are conducted to show the influences of the CNT volume fraction, CNT distribution type, slenderness ratio, boundary condition, and elastic foundation coefficients on the nonlinear vibration behavior of the FG-CNTRC beams resting on a nonlinear elastic foundation.
In addition, the effects of the temperature rise and the initial thermal stress are also discussed.

In what follows, otherwise specified, the CNTRC beam considered here is made of the PMMA matrix and $(10,10)$ armchair SWCNT reinforcements. The material properties of the PMMA matrix are assumed to be temperaturedependent and are given by

$$
\begin{aligned}
E^{\mathrm{m}} & =(3.52-0.0034 T) \mathrm{GPa}, \\
\rho^{\mathrm{m}} & =1190\left(\mathrm{~kg} / \mathrm{m}^{3}\right), \\
\nu^{m} & =0.3, \\
\alpha^{\mathrm{m}} & =45(1+0.0005 \Delta T) \times 10^{-6} / \mathrm{K},
\end{aligned}
$$

where $T=T_{0}+\Delta T$ and $T_{0}$ is the room temperature, which is assumed to be $T_{0}=300 \mathrm{~K}$ and those of SWCNTs at the given temperatures are listed in Table 1. To establish a temperature-dependent relationship, a third-order interpolation is used to estimate the material properties of SWCNTs as a function of temperature. For $300 \leq T \leq 1000$, the variations of the material properties of SWCNTs with respect to the temperature are as follows:

$$
\begin{aligned}
E_{11}^{\mathrm{CNT}}= & 6.15145-2.6591 \times 10^{-3} \mathrm{~T}+3.882 \times 10^{-6} T^{2} \\
& -2.093095 \times 10^{-9} T^{3}(\mathrm{TPa}), \\
E_{22}^{\mathrm{CNT}}= & 7.71322-3.3355 \times 10^{-3} \mathrm{~T}+4.870 \times 10^{-6} T^{2} \\
& -2.626071 \times 10^{-9} T^{3}(\mathrm{TPa}), \\
G_{12}^{\mathrm{CNT}}= & 1.86037+4.1425 \times 10^{-4} \mathrm{~T}-4.961 \times 10^{-7} T^{2} \\
& +1.66548 \times 10^{-10} T^{3}(\mathrm{TPa}), \\
\alpha_{11}^{\mathrm{CNT}}= & -1.12092+2.2888 \times 10^{-2} \mathrm{~T}-2.881 \times 10^{-5} \mathrm{~T}^{2} \\
& +1.13223 \times 10^{-8} \mathrm{~T}^{3}\left(\times 10^{-6} / \mathrm{K}\right), \\
v_{12}^{\mathrm{CNT}}= & 0.175, \\
\rho^{\mathrm{CNT}}= & 1400 \mathrm{~kg} / \mathrm{m}^{3} .
\end{aligned}
$$

For three different CNT volume fractions, the CNT efficiency parameters $\eta_{i}(i=1,2,3)$ are as follows: $\eta_{1}=0.137$, $\eta_{2}=1.022$, and $\eta_{3}=0.715$ for $V_{\mathrm{CNT}}^{*}=0.12 ; \eta_{1}=0.142$, $\eta_{2}=1.626$, and $\eta_{3}=1.138$ for $V_{\mathrm{CNT}}^{*}=0.17 ; \eta_{1}=0.141$, $\eta_{2}=1.585$, and $\eta_{3}=1.109$ for $V_{\mathrm{CNT}}^{*}=0.28$.

For simplicity, the letters $\mathrm{C}$ and $\mathrm{H}$ are used to denote clamped and hinged boundary conditions, respectively. For instance, $\mathrm{C}-\mathrm{H}$ represents the beam with one end clamped and the other end hinged. The dimensionless stiffness coefficients of the elastic foundation are defined as follows:

$$
\begin{gathered}
K_{\mathrm{L}}=\frac{k_{\mathrm{L}} L^{2}}{A_{110}}, \\
K_{\mathrm{NL}}=\frac{k_{\mathrm{NL}} H^{4}}{A_{110}}, \\
K_{\mathrm{S}}=\frac{k_{\mathrm{S}}}{A_{110}},
\end{gathered}
$$


TABle 1: Temperature-dependent material properties of $(10,10)$ armchair SWCNTs.

\begin{tabular}{lcccc}
\hline $\begin{array}{l}T \\
(\mathrm{~K})\end{array}$ & $\begin{array}{c}E_{11}^{\mathrm{CNT}} \\
(\mathrm{TPa})\end{array}$ & $\begin{array}{c}E_{22}^{\mathrm{CNT}} \\
(\mathrm{TPa})\end{array}$ & $\begin{array}{c}G_{12}^{\mathrm{CNT}} \\
(\mathrm{TPa})\end{array}$ & $\begin{array}{c}\alpha_{11}^{\mathrm{CNT}} \\
\left(\times 10^{-6} / \mathrm{K}\right)\end{array}$ \\
\hline 300 & 5.6466 & 7.0800 & 1.9445 & 3.4584 \\
500 & 5.5308 & 6.9348 & 1.9643 & 4.5361 \\
700 & 5.4744 & 6.8641 & 1.9644 & 4.6677 \\
1000 & 5.2814 & 6.6220 & 1.9451 & 4.2800 \\
\hline
\end{tabular}

where $A_{110}=E^{\mathrm{m} 0} H /\left[1-\left(\nu^{\mathrm{m}}\right)^{2}\right]$, where $E^{\mathrm{m} 0}$ is the value of $E^{\mathrm{m}}$ at room temperature.

4.1. Convergence and Comparison Studies. In this subsection, the convergence of the proposed method for the vibration analysis of FG-CNTRC beams is first examined to establish the maximal level of resolution $J$ of the truncated Haar wavelet series to achieve accurate results. Table 2 presents the linear fundamental frequency parameters $\Omega_{\mathrm{L}}$ of C-C FG-CNTRC beams with varying maximal level of resolution $J$. The linear fundamental frequency parameters $\Omega_{\mathrm{L}}$ are defined as $\Omega_{\mathrm{L}}=\omega_{\mathrm{L}} L \sqrt{\rho^{\mathrm{m}} H / A_{110}}$. The geometrical sizes are $H=0.1 \mathrm{~m}$ and $L / H=25$. The material properties used are defined in Equations (30) and (31) at room temperature. As a comparison, the results available in Ref. [18] are also included in Table 2. It can be seen from this table that, by increasing the maximal level of resolution $J$, the numerical results converge stably and the converged values are in close agreement with those of Ref. [18]. In addition, based on the obtained frequency results for three successive values of $J$, the numerical rate of convergence can be estimated as follows [36]:

$$
k_{i}=\frac{\log \left(\left(R_{i-2}-R_{i-1}\right) /\left(R_{i-1}-R_{i}\right)\right)}{\log (2)},
$$

where $R_{i}$ is the obtained result in the case of $J=i$. Here, the estimated rates of convergence are also listed in Table 2 and it is observed that the numerical rates of convergence tend to two for all the cases, which is in agreement with the theoretical result given in Ref. [44]. Moreover, it can be noted that the results obtained are nearly unchanged with the increase in $J$ when it reaches a certain value of $J=7$. Thus, unless otherwise stated, the maximal level of resolution is chosen as $J=7$ in the following examples.

A comparison study is presented in the next example for $\mathrm{H}-\mathrm{H}$ FG-CNTRC beams resting on linear elastic foundations with various elastic foundation coefficients. The first three linear frequency parameters $\Omega_{i}=\omega_{i} L \sqrt{\rho^{\mathrm{m}} H / A_{110}}(i=1,2,3)$ are evaluated and compared with the available results in the open literature, as shown in Table 3. The material properties used are taken from Ref. [23], and the geometrical parameters are $H=0.1 \mathrm{~m}$ and $L / H=15$. It can be seen that the obtained frequency parameters are in good agreement with the available results in the open literature [23].
In the next example, the nonlinear frequency ratios $\omega_{\mathrm{NL}} / \omega_{\mathrm{L}}$ at different dimensionless vibration amplitude $W_{\max }^{*}$ are given in Table 4 for UD-CNTRC beams with different boundary conditions and compared with those given by the open literature. The dimensionless vibration amplitude $W_{\max }^{*}$ is defined as $W_{\max }^{*}=W_{\max } / H$, where $W_{\max }$ denotes the vibration amplitude. The material properties used are the same with those given by Ke et al. [16]. As can be seen, our results are in excellent agreement with those obtained by Ke et al. [16] and Lin et al. [45].

The convergence and comparison studies show the excellent convergence and accuracy of the proposed Haar wavelet method for the nonlinear vibration analysis of FGCNTRC beams.

4.2. Parametric Studies. In this subsection, parametric studies will be presented to examine the nonlinear vibration behaviors of FG-CNTRC beams resting on a nonlinear elastic foundation. In the rest of the manuscript, the material properties of CNTRC are taken as the values in Equations (30) and (31).

As a first case, the effects of the distribution and volume fraction of CNTs together with the boundary condition on the nonlinear vibration behaviors of FGCNTRC beams are examined. Table 5 presents the linear fundamental frequency parameters and nonlinear frequency ratios $\omega_{\mathrm{NL}} / \omega_{\mathrm{L}}$ at different dimensionless vibration amplitude with various distribution types of CNTs, various CNT volume fractions, and different boundary conditions. Three kinds of boundary conditions (C-C, $\mathrm{C}-\mathrm{H}$, and $\mathrm{H}-\mathrm{H}$ ) are considered. Tabulated results are given for CNTRC beams with $H=0.1 \mathrm{~m}$ and $L / H=25$ resting on a nonlinear elastic foundation at room temperature. The stiffness coefficients of the foundation are $K_{\mathrm{L}}=10, K_{\mathrm{NL}}=0.1$, and $K_{\mathrm{S}}=0.02$. It is seen from the table that the nonlinear frequency ratio increases with an increase in vibration amplitude, showing the well-known "hard spring" vibration behavior. Among the CNT distributions considered here, FG-X leads to the highest linear fundamental frequency, followed by UD and FG-O, but for the nonlinear frequency ratios $\omega_{\mathrm{NL}} / \omega_{\mathrm{L}}, \mathrm{FG}-\mathrm{O}$ yields the highest value, followed by UD and FG-X. This can be explained by the fact that the CNT reinforcements distributed close to the top and bottom are more efficient than those distributed near the midplane for increasing the stiffness of CNTRC beams. Besides, for all the boundary conditions considered, the C-C beam has the highest linear fundamental frequency but lowest nonlinear frequency ratios, followed by $\mathrm{C}-\mathrm{H}$ and then $\mathrm{H}-\mathrm{H}$ beams. It can also be seen that the linear fundamental frequency increases with an increase in the CNT volume fraction, but it is unexpected that the CNTRC beams with $V_{\text {CNT }}^{*}=0.17$, rather than $V_{\mathrm{CNT}}^{*}=0.12$, have the lowest frequency ratio. This phenomenon was also found by $\mathrm{Wu}$ et al. [18]. 
TABLE 2: Convergence of linear fundamental frequency parameters $\Omega_{\mathrm{L}}$ for C-C FG-CNTRC beams $(H=0.1 \mathrm{~m}, L / H=25$, and $K_{\mathrm{L}}=K_{\mathrm{NL}}=K_{\mathrm{S}}=0$; the number in parenthesis indicates the estimated rate of convergence).

\begin{tabular}{|c|c|c|c|c|c|c|c|}
\hline \multirow{2}{*}{$V_{\mathrm{CNT}}^{*}$} & \multirow{2}{*}{ Type } & \multicolumn{5}{|c|}{ Present } & \multirow{2}{*}{ Ref. [18] } \\
\hline & & $J=4$ & $J=5$ & $J=6$ & $J=7$ & $J=8$ & \\
\hline \multirow{3}{*}{0.12} & FG-X & 1.175828 & 1.173992 & $1.173533(2.000)$ & $1.173417(1.984)$ & $1.173389(2.051)$ & 1.1733 \\
\hline & UD & 1.073922 & 1.071476 & $1.070863(1.996)$ & $1.070709(1.993)$ & $1.070671(2.019)$ & 1.0706 \\
\hline & FG-O & 0.887362 & 0.883423 & $0.882435(1.995)$ & $0.882188(2.000)$ & $0.882126(1.994)$ & 0.8821 \\
\hline \multirow{3}{*}{0.28} & FG-X & 1.691824 & 1.689592 & $1.689034(2.000)$ & $1.688894(1.995)$ & $1.688859(2.000)$ & 1.6887 \\
\hline & UD & 1.536038 & 1.533217 & $1.532510(1.996)$ & 1.532333 (1.998) & $1.532289(2.008)$ & 1.5322 \\
\hline & FG-O & 1.297611 & 1.292688 & $1.291453(1.995)$ & $1.291144(1.999)$ & $1.291067(2.005)$ & 1.2911 \\
\hline
\end{tabular}

TABLE 3: Comparison of the first three dimensionless linear frequency parameters for CNTRC beams resting on linear elastic foundations $\left(V_{\mathrm{CNT}}^{*}=0.12, L / H=15, H=0.1 \mathrm{~m}\right.$, and $K_{\mathrm{NL}}=0$; boundary condition: $\left.\mathrm{H}-\mathrm{H}\right)$.

\begin{tabular}{|c|c|c|c|c|c|c|c|c|c|c|}
\hline \multirow{2}{*}{ Type } & & \multicolumn{3}{|c|}{$\left(K_{\mathrm{L}}=0, K_{\mathrm{S}}=0\right)$} & \multicolumn{3}{|c|}{$\left(K_{\mathrm{L}}=0.1, K_{\mathrm{S}}=0\right)$} & \multicolumn{3}{|c|}{$\left(K_{\mathrm{L}}=0.1, K_{\mathrm{S}}=0.02\right)$} \\
\hline & & $\Omega_{1}$ & $\Omega_{2}$ & $\Omega_{3}$ & $\Omega_{1}$ & $\Omega_{2}$ & $\Omega_{3}$ & $\Omega_{1}$ & $\Omega_{2}$ & $\Omega_{3}$ \\
\hline \multirow{2}{*}{ UD } & Present & 0.9739 & 2.8641 & 4.8515 & 1.0229 & 2.8811 & 4.8616 & 1.1132 & 3.0120 & 5.0371 \\
\hline & Ref. [23] & 0.9753 & 2.8728 & 4.8704 & 1.0241 & 2.8898 & 4.8804 & 1.1144 & 3.0203 & 5.0552 \\
\hline \multirow{2}{*}{ FG-X } & Present & 1.1129 & 3.0702 & 5.0473 & 1.1560 & 3.0860 & 5.0570 & 1.2367 & 3.2087 & 5.2261 \\
\hline & Ref. [23] & 1.1150 & 3.0814 & 5.0695 & 1.1581 & 3.0972 & 5.0791 & 1.2386 & 3.2194 & 5.2474 \\
\hline \multirow{2}{*}{ FG-O } & Present & 0.7521 & 2.4507 & 4.4175 & 0.8145 & 2.4705 & 4.4285 & 0.9253 & 2.6216 & 4.6200 \\
\hline & Ref. [23] & 0.7527 & 2.4562 & 4.4320 & 0.8150 & 2.4760 & 4.4430 & 0.9258 & 2.6268 & 4.6338 \\
\hline
\end{tabular}

TABLE 4: Comparison of nonlinear to linear frequency ratios $\omega_{\mathrm{NL}} / \omega_{\mathrm{L}}$ for UD-CNTRC beams with different boundary conditions $\left(V_{\mathrm{CNT}}^{*}=0.17, H=0.1 \mathrm{~m}\right.$, and $\left.L / H=10\right)$.

\begin{tabular}{lcccccccc}
\hline$W_{\text {max }}^{*}$ & Ke et al. [16] & Lin et al. [45] & Present & Ke et al. [16] & $\begin{array}{c}\text { C-C } \\
\text { Lin et al. [45] }\end{array}$ & Present & Ke et al. [16] & $\begin{array}{c}\text { C-H } \\
\text { Lin et al. [45] }\end{array}$ Present \\
\hline 0.1 & 1.0259 & 1.0261 & 1.0260 & 1.0136 & 1.0136 & 1.0136 & 1.0187 & 1.0188 \\
0.2 & 1.1000 & 1.1005 & 1.1004 & 1.0533 & 1.0537 & 1.0535 & 1.0727 & 1.0731 \\
0.3 & 1.2135 & 1.2144 & 1.2144 & 1.1165 & 1.1175 & 1.1173 & 1.1570 & 1.1580 \\
0.4 & 1.3565 & 1.3579 & 1.3577 & 1.2001 & 1.2016 & 1.2015 & 1.2657 & 1.2671 \\
0.5 & 1.5206 & 1.5227 & 1.5223 & 1.3036 & 1.3019 & 1.3022 & 1.3922 & 1.3951 \\
\hline
\end{tabular}

The influences of the slenderness ratio on the linear fundamental frequency parameters and nonlinear frequency ratios $\omega_{\mathrm{NL}} / \omega_{\mathrm{L}}$ of the FG-CNTRC beams with and without elastic foundation are investigated in Table 6 . The results are provided for the FG-X CNTRC beam with $V_{\mathrm{CNT}}^{*}=0.17$ and $H=0.1 \mathrm{~m}$ subjected to the $\mathrm{H}-\mathrm{H}$ boundary condition at room temperature. It is found that the linear fundamental frequency parameter decreases with an increase in the slenderness ratio. For the beam without the elastic foundation, the increase in the slenderness ratio yields a decrease in the nonlinear frequency ratio, but, for the beam resting on the nonlinear elastic foundation, the nonlinear frequency ratio firstly decreases and then increases with an increase in the slenderness ratio.

Next, the effects of the stiffness coefficients of the nonlinear elastic foundation on the nonlinear vibration behaviors of FG-CNTRC are studied. The variations of the nonlinear frequency ratio of FG-X CNTRC beams against the dimensionless vibration amplitude are displayed in Figure 3 for different stiffness coefficients. The corresponding dimensionless linear fundamental frequencies are also shown in Figure 3. The obtained results are given for the $\mathrm{H}-\mathrm{H}$ beam with $H=0.1 \mathrm{~m}$ and $\mathrm{L} / H=25$ resting on a nonlinear elastic foundation at room temperature. The volume fraction of CNTs is taken as $V_{\mathrm{CNT}}^{*}=0.28$. It can be seen from Figure 3(a) that the linear fundamental frequency increases and the nonlinear frequency ratio decreases with an increase in the linear stiffness coefficient $K_{\mathrm{L}}$. The same trend is also observed from Figure 3(c) for the shear stiffness coefficient $K_{\mathrm{S}}$. It can be noted that, different from the above two linear elastic coefficients, an increase in the nonlinear stiffness coefficient $K_{\mathrm{NL}}$ leads to a larger nonlinear frequency ratio, but the linear fundamental frequency remains constant.

In the following, the effects of the temperature rise and initial thermal stress on the nonlinear vibration behavior of FG-CNTRC beams on nonlinear elastic foundations are discussed.

In Figure 4, the variations of the dimensionless linear fundamental frequency against the temperature rise with and without considering the initial thermal stress are compared. Three kinds of elastic foundations are considered. It can be seen from Figure 4 that as the 
TABLE 5: Nonlinear frequency ratio $\omega_{\mathrm{NL}} / \omega_{\mathrm{L}}$ of FG-CNTRC beams resting on the nonlinear elastic foundation with different boundary conditions $\left(H=0.1 \mathrm{~m}, L / H=25, K_{\mathrm{L}}=10, K_{\mathrm{NL}}=0.1, K_{\mathrm{S}}=0.02\right.$, and $T=300(\mathrm{~K})$.

\begin{tabular}{|c|c|c|c|c|c|c|c|c|}
\hline \multirow{2}{*}{ B.C. } & \multirow{2}{*}{ Type } & \multirow{2}{*}{$V_{\mathrm{CNT}}^{*}$} & \multirow{2}{*}{$\Omega_{\mathrm{L}}$} & \multicolumn{5}{|c|}{$W_{\max }^{*}$} \\
\hline & & & & 0.1 & 0.2 & 0.3 & 0.4 & 0.5 \\
\hline \multirow{9}{*}{$\mathrm{C}-\mathrm{C}$} & \multirow{3}{*}{ UD } & 0.12 & 1.7914 & 1.0252 & 1.0976 & 1.2097 & 1.3522 & 1.5160 \\
\hline & & 0.17 & 2.2691 & 1.0209 & 1.0815 & 1.1762 & 1.2976 & 1.4409 \\
\hline & & 0.28 & 2.4750 & 1.0258 & 1.1001 & 1.2147 & 1.3598 & 1.5299 \\
\hline & \multirow{3}{*}{ FG-X } & 0.12 & 1.8346 & 1.0241 & 1.0936 & 1.2015 & 1.3389 & 1.4983 \\
\hline & & 0.17 & 2.3411 & 1.0198 & 1.0771 & 1.1670 & 1.2826 & 1.4192 \\
\hline & & 0.28 & 2.5831 & 1.0239 & 1.0926 & 1.1991 & 1.3346 & 1.4919 \\
\hline & \multirow{3}{*}{ FG-O } & 0.12 & 1.6944 & 1.0279 & 1.1078 & 1.2309 & 1.3859 & 1.5643 \\
\hline & & 0.17 & 2.1302 & 1.0236 & 1.0915 & 1.1971 & 1.3315 & 1.4869 \\
\hline & & 0.28 & 2.3952 & 1.0273 & 1.1057 & 1.2263 & 1.3775 & 1.5529 \\
\hline \multirow{9}{*}{$\mathrm{C}-\mathrm{H}$} & \multirow{3}{*}{ UD } & 0.12 & 1.6120 & 1.0314 & 1.1208 & 1.2567 & 1.4263 & 1.6464 \\
\hline & & 0.17 & 2.0163 & 1.0269 & 1.1039 & 1.2219 & 1.3708 & 1.5408 \\
\hline & & 0.28 & 2.2349 & 1.0321 & 1.1231 & 1.2609 & 1.4315 & 1.6333 \\
\hline & \multirow{3}{*}{ FG-X } & 0.12 & 1.6817 & 1.0290 & 1.1116 & 1.2380 & 1.3967 & 1.5848 \\
\hline & & 0.17 & 2.1223 & 1.0243 & 1.0942 & 1.2022 & 1.3390 & 1.5013 \\
\hline & & 0.28 & 2.3713 & 1.0286 & 1.1101 & 1.2346 & 1.3908 & 1.5685 \\
\hline & \multirow{3}{*}{ FG-O } & 0.12 & 1.4697 & 1.0379 & 1.1442 & 1.3032 & 1.4988 & 1.7438 \\
\hline & & 0.17 & 1.8160 & 1.0333 & 1.1274 & 1.2692 & 1.4450 & 1.6678 \\
\hline & & 0.28 & 2.0742 & 1.0373 & 1.1419 & 1.2985 & 1.4909 & 1.7407 \\
\hline \multirow{9}{*}{$\mathrm{H}-\mathrm{H}$} & \multirow{3}{*}{ UD } & 0.12 & 1.4598 & 1.0385 & 1.1465 & 1.3078 & 1.5056 & 1.7281 \\
\hline & & 0.17 & 1.7909 & 1.0342 & 1.1308 & 1.2763 & 1.4558 & 1.6588 \\
\hline & & 0.28 & 2.0430 & 1.0385 & 1.1465 & 1.3075 & 1.5037 & 1.7279 \\
\hline & \multirow{3}{*}{ FG-X } & 0.12 & 1.5712 & 1.0333 & 1.1276 & 1.2701 & 1.4469 & 1.6464 \\
\hline & & 0.17 & 1.9521 & 1.0289 & 1.1111 & 1.2366 & 1.3936 & 1.5730 \\
\hline & & 0.28 & 2.2273 & 1.0325 & 1.1246 & 1.2637 & 1.4357 & 1.6308 \\
\hline & \multirow{3}{*}{ FG-O } & 0.12 & 1.2490 & 1.0522 & 1.1956 & 1.4037 & 1.6525 & 1.9255 \\
\hline & & 0.17 & 1.5018 & 1.0483 & 1.1817 & 1.3763 & 1.6099 & 1.8698 \\
\hline & & 0.28 & 1.7611 & 1.0515 & 1.1930 & 1.3981 & 1.6431 & 1.9131 \\
\hline
\end{tabular}

temperature rise increases, the linear fundamental frequency parameter decreases monotonically to zero. In the case considering the initial thermal stress, the decrease in the linear fundamental frequency parameter is much rapider than that without considering the initial thermal stress. The zero values of the dimensionless linear fundamental frequency represent the onset of instability or buckling of the beams, and the corresponding temperature is the critical temperature at which the beam begins to be instable or buckled. Besides, it is found that, by increasing the linear and shear stiffness coefficients, both the linear fundamental frequency and the critical temperature increase.

Figure 5 presents the variations of the nonlinear frequency ratio of FG-CNTRC beams against the dimensionless vibration amplitude under different temperature rises. Both the case with and without the initial thermal stress are taken into consideration. It is found that the nonlinear frequency ratio increases with an increase in the temperature rise. In addition, when the initial thermal stress is considered, the nonlinear frequency ratio increases.

As can be seen from Figures 4 and 5, the initial thermal stress has remarkable effects on the nonlinear vibration behavior of FG-CNTRC beams and hence cannot be neglected when CNTRCs are operating in a thermal environment.

\section{Conclusion}

The nonlinear vibration behavior of FG-CNTRC beams resting on a nonlinear elastic foundation in a thermal environment was investigated in this paper using the HWDM. The FSDT together with the von Kármán nonlinearity was adopted to model the kinematic relationships. Both the initial thermal stress and the temperature dependence of the material properties were considered in the theoretical modeling. The nonlinear governing equations of CNTRC beams on nonlinear elastic foundations were derived and then solved using the HWDM in conjunction with the direct iteration technique to obtain the linear and nonlinear natural frequencies. The convergence and accuracy studies were conducted, and the results revealed that the numerically estimated rate of convergence of the proposed method tends to two, which is consistent with the convergence theorem, and good accuracy of the proposed method is confirmed by comparing the present results with those available in the literature. Finally, parametrical studies were carried out to explore the influences of the volume fraction of CNTs, distribution type of CNTs, slenderness ratio, boundary conditions, foundation stiffness coefficients, temperature rise, and initial thermal stress on the nonlinear vibration behavior of FG-CNTRC beams. The following conclusions can be carried out: 
TABLE 6: Effects of the slenderness ratio on $\omega_{\mathrm{NL}} / \omega_{\mathrm{L}}$ of $\mathrm{H}-\mathrm{H}$ FG-X CNTRC beams with and without the elastic foundation $\left(V_{\mathrm{CNT}}^{*}=0.17\right.$, $H=0.1 \mathrm{~m}$, and $T=300(\mathrm{~K})$.

\begin{tabular}{|c|c|c|c|c|c|c|c|c|c|c|c|c|}
\hline \multirow{3}{*}{$L / H$} & \multicolumn{6}{|c|}{ Without the elastic foundation $\left(K_{\mathrm{L}}=K_{\mathrm{NL}}=K_{\mathrm{S}}=0\right)$} & \multicolumn{6}{|c|}{ With the elastic foundation $\left(K_{\mathrm{L}}=10, K_{\mathrm{NL}}=0.1, K_{\mathrm{S}}=0.02\right)$} \\
\hline & \multirow{2}{*}{$\Omega_{\mathrm{L}}$} & \multicolumn{5}{|c|}{$W_{\max }^{*}$} & \multirow{2}{*}{$\Omega_{\mathrm{L}}$} & \multicolumn{5}{|c|}{$W_{\max }^{*}$} \\
\hline & & 0.1 & 0.2 & 0.3 & 0.4 & 0.5 & & 0.1 & 0.2 & 0.3 & 0.4 & 0.5 \\
\hline 10 & 2.2986 & 1.1000 & 3566 & 6999 & 2.0864 & 2.4935 & 2.3606 & 10957 & 13424 & 1.6740 & 2.0478 & 2.4409 \\
\hline 20 & 2.0271 & 1.0332 & 1.1270 & 1.2680 & 1.4424 & 1.6395 & 2.0971 & 1.0343 & 1.1310 & 1.2760 & 1.4544 & 1.6622 \\
\hline 30 & 1.7316 & 1.0204 & 1.0791 & 706 & 1.2877 & 1.4242 & 1.8130 & 1.0283 & 1.1 & 1.2330 & 1.3888 & 1.5671 \\
\hline 40 & 1.4749 & 1.0158 & 1.0619 & 1.1345 & 1.2289 & 1.3406 & 1.5698 & 1.0371 & 1.1415 & 1.2984 & 1.4924 & 1.7117 \\
\hline 50 & 1.2681 & 1.0137 & 1.0538 & 1.1174 & 1.2007 & 1.3001 & 1.3772 & 1.0581 & 1.2169 & 1.4459 & 1.7201 & 2.0237 \\
\hline
\end{tabular}

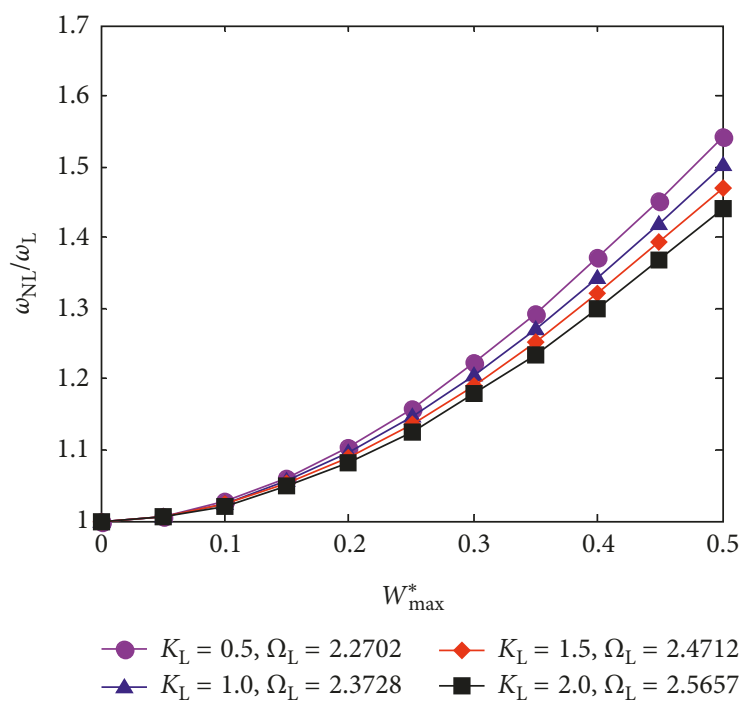

(a)

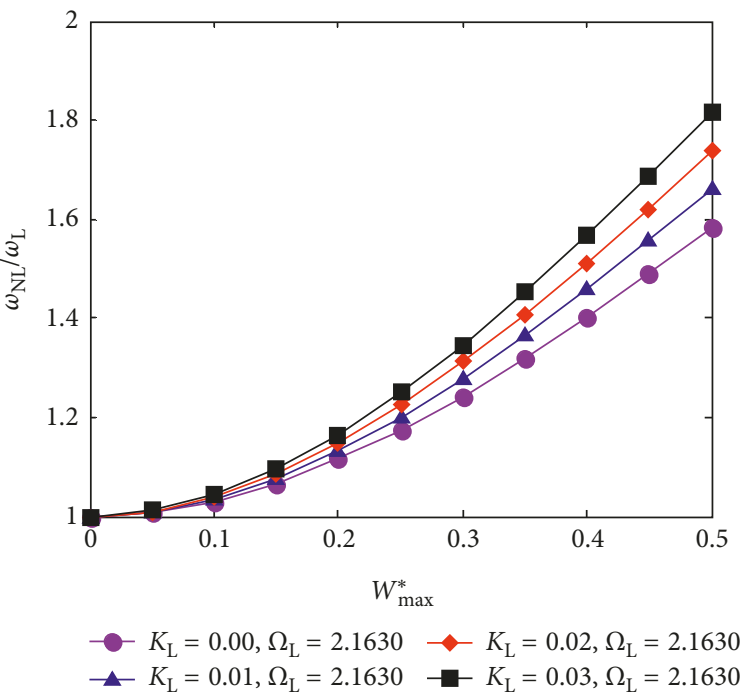

(b)

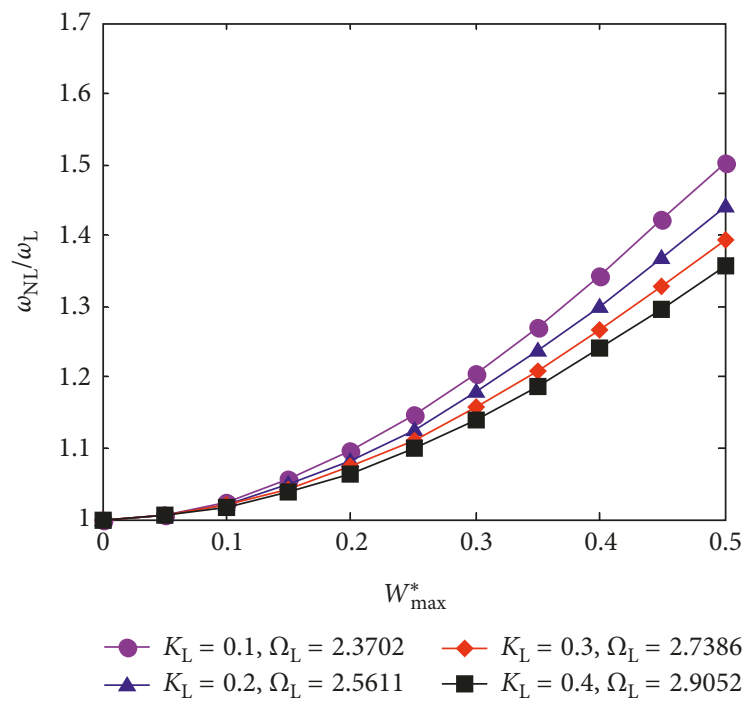

(c)

FIGURE 3: Nonlinear frequency ratios versus dimensionless vibration amplitude of H-H FG-CNTRC beams for different values of elastic foundation coefficients $\left(H=0.1 \mathrm{~m}, L / H=25, V_{\mathrm{CNT}}^{*}=0.28\right.$, FG-X, and $\left.T=300 \mathrm{~K}\right)$ : (a) $K_{\mathrm{L}}\left(K_{\mathrm{NL}}=K_{\mathrm{S}}=0\right)$; $(\mathrm{b}) K_{\mathrm{NL}}\left(K_{\mathrm{L}}=K_{\mathrm{S}}=0\right)$; (c) $K_{\mathrm{s}}$ $\left(K_{\mathrm{L}}=K_{\mathrm{NL}}=0\right)$.

(a) The beams with FG-X CNT distribution have the highest linear fundamental frequency but lowest nonlinear frequency ratios, followed by UD and then FG-O beams (b) The $\mathrm{C}-\mathrm{C}$ beam has the highest linear fundamental frequency but lowest nonlinear frequency ratios, followed by $\mathrm{C}-\mathrm{H}$ and then $\mathrm{H}-\mathrm{H}$ beams 


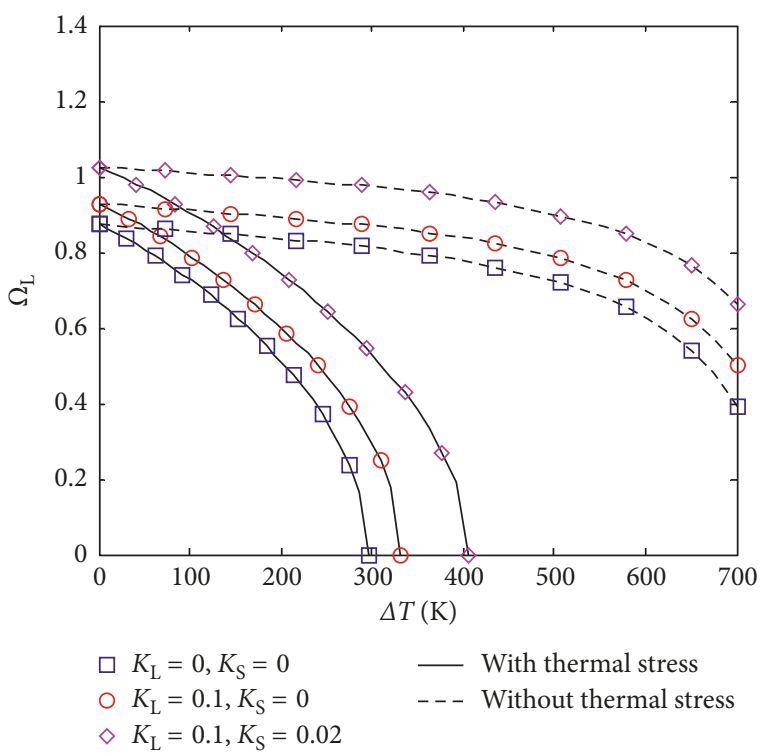

FIgURE 4: The effect of the temperature rise together with the initial thermal stress on the dimensionless linear fundamental frequency of FG-CNTRC beams with various elastic foundations $\left(H=0.1 \mathrm{~m}, L / H=25, K_{\mathrm{NL}}=0\right.$, and $V_{\mathrm{CNT}}^{*}=0.17, \mathrm{FG}-\mathrm{X}$; boundary condition: $\mathrm{H}-\mathrm{H})$.

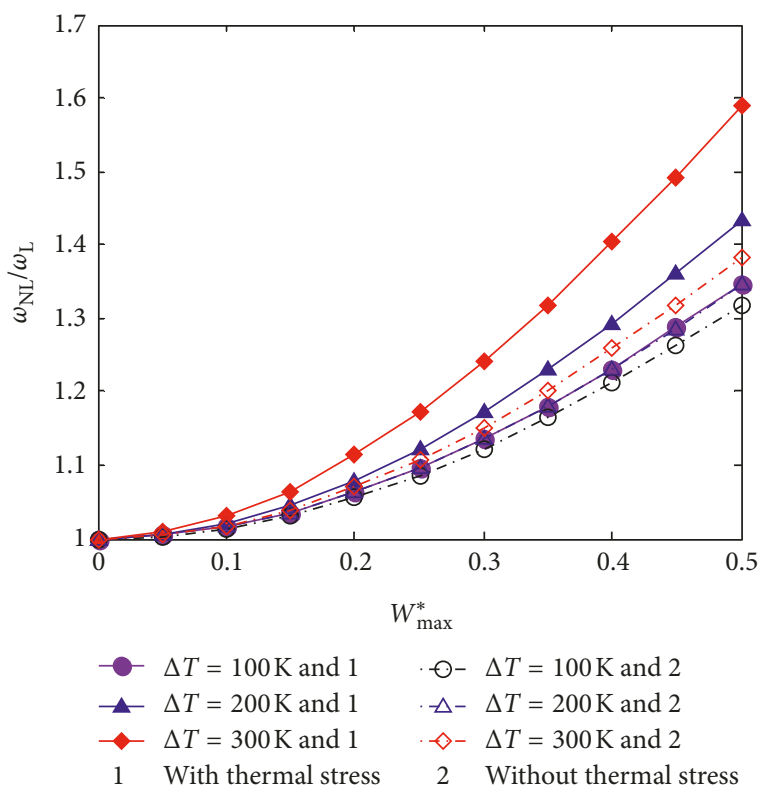

FIGURE 5: The effect of the temperature rise together with the initial thermal stress on the nonlinear frequency ratio of FG-CNTRC beams $\left(H=0.1 \mathrm{~m}, L / H=25, \quad K_{\mathrm{L}}=10, K_{\mathrm{NL}}=\right.$ $10, K_{\mathrm{S}}=0.1$, and $V_{\mathrm{CNT}}^{*}=0.17$, FG-X; boundary condition: $\mathrm{H}-\mathrm{H})$.

(c) The linear fundamental frequency increases with an increase in the CNT volume fraction or a decrease in the slenderness ratio (d) The linear fundamental frequency increases and the nonlinear frequency ratio decreases with an increase in the linear or shear stiffness coefficients of the foundation; the increase in the nonlinear stiffness coefficient of the foundation yields larger nonlinear frequency ratio, but the linear fundamental frequency remains constant

(e) By increasing the temperature rise, the linear fundamental frequency decreases, yet the nonlinear frequency ratio increases

(f) The initial thermal stresses have significant effects on the nonlinear vibration behavior of CNTRC beams and cannot be neglected

This study offers an insight into the nonlinear vibration behaviors of CNTRC beams resting on nonlinear elastic foundations in a thermal environment.

\section{Appendix}

\section{A. Detailed Expressions of the Constant Coefficients in the Governing Equations}

The coefficients in Equation (15) are given by

$$
\begin{aligned}
& L_{1}=\frac{A_{11}}{L^{2}}, \\
& L_{2}=\frac{B_{11}}{L^{2}} \\
& L_{3}=\frac{\kappa A_{55}}{L^{2}}, \\
& L_{4}=\frac{\kappa A_{55}}{L}, \\
& L_{5}=\frac{D_{11}}{L^{2}}, \\
& L_{6}=-\frac{\kappa A_{55}}{L}, \\
& L_{7}=-\kappa A_{55}, \\
& G_{1}=\frac{A_{11}}{L^{3}}, \\
& G_{2}=\frac{B_{11}}{L^{3}}, \\
& G_{3}=\frac{3 A_{11}}{2 L^{4}}, \\
& G_{T}=\int_{-h / 2}^{h / 2}, Q_{11}(z, T) \alpha_{11}(z, T) d z .
\end{aligned}
$$




\section{B. Detailed Expressions of the Submatrices in} the Mass and Stiffness Matrices

The coefficient matrices defined in Equation (24) are given by

$$
\begin{aligned}
& \mathbf{K}_{\mathbf{d d}}^{s}=\left[\begin{array}{ccc}
L_{1} \mathbf{H} & 0 & L_{2} \mathbf{H} \\
0 & L_{3} \mathbf{H}-k_{\mathrm{L}} \mathbf{P}_{2}+\frac{k_{\mathrm{S}}}{L^{2}} \mathbf{H} & L_{4} \mathbf{P}_{1} \\
L_{2} \mathbf{H} & L_{6} \mathbf{P}_{1} & L_{5} \mathbf{H}+L_{7} \mathbf{P}_{2}
\end{array}\right] \text {, } \\
& \mathbf{K}_{\text {bd }}^{\mathbf{s}}=\left[\begin{array}{ccc}
0 & 0 & 0 \\
0 & -k_{L} \mathbf{Q}_{2} & L_{4} \mathbf{Q}_{1} \\
0 & L_{6} \mathbf{Q}_{1} & L_{7} \mathbf{Q}_{2}
\end{array}\right] \text {, } \\
& \mathbf{K}_{\mathbf{d d}}^{\mathbf{t}}=\left[\begin{array}{ccc}
0 & 0 & 0 \\
0 & G_{\mathrm{T}} \mathbf{H} & 0 \\
0 & 0 & 0
\end{array}\right] \text {, }
\end{aligned}
$$

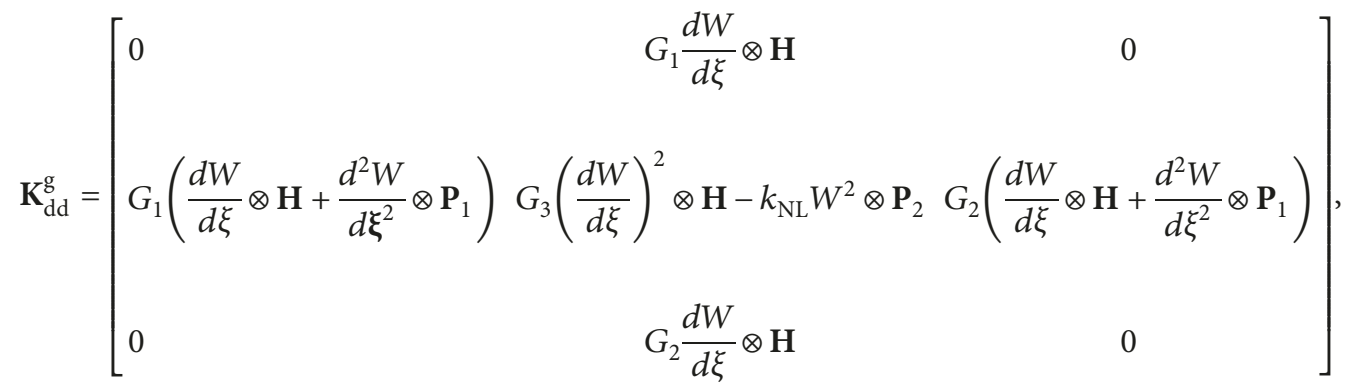

$$
\begin{aligned}
& \mathbf{K}_{\mathbf{b d}}^{\mathbf{g}}=\left[\begin{array}{ccc}
0 & 0 & 0 \\
G_{1} \frac{d^{2} W}{d \xi^{2}} \otimes \mathbf{Q}_{1} & -k_{\mathrm{NL}} W^{2} \otimes \mathbf{Q}_{2} & G_{2} \frac{d^{2} W}{d \xi^{2}} \otimes \mathbf{Q}_{1} \\
0 & 0 & 0
\end{array}\right] \text {, } \\
& \mathbf{M}_{\mathbf{d d}}=-\left[\begin{array}{ccc}
I_{0} \mathbf{P}_{2} & 0 & I_{1} \mathbf{P}_{2} \\
0 & I_{0} \mathbf{P}_{2} & 0 \\
I_{1} \mathbf{P}_{2} & 0 & I_{2} \mathbf{P}_{2}
\end{array}\right] \text {, } \\
& \mathbf{M}_{\mathbf{b d}}=-\left[\begin{array}{ccc}
I_{0} \mathbf{Q}_{2} & 0 & I_{1} \mathbf{Q}_{2} \\
0 & I_{0} \mathbf{Q}_{2} & 0 \\
I_{1} \mathbf{Q}_{2} & 0 & I_{2} \mathbf{Q}_{2}
\end{array}\right] \text {, }
\end{aligned}
$$


where $\otimes$ stands for the product of a vector and a matrix and is defined as follows:

$$
\mathbf{C}=\mathbf{a} \otimes \mathbf{B}=\left[a_{i} B_{i j}\right]_{N \times M}, \quad \text { for } \mathbf{a}=\left[a_{i}\right]_{N \times 1} \text { and } \mathbf{B}=\left[B_{i j}\right]_{N \times M} .
$$

The coefficient matrices of a clamped beam at both ends defined in Equation (26) can be expressed as

$$
\begin{aligned}
& \mathbf{K}_{\mathbf{d b}}^{\mathbf{s}}=\left[\begin{array}{ccc}
\mathbf{C}_{1} & 0 & 0 \\
0 & \mathbf{C}_{1} & 0 \\
0 & 0 & \mathbf{C}_{1}
\end{array}\right], \\
& \mathbf{K}_{\mathbf{d b}}^{\mathbf{s}}=\left[\begin{array}{ccc}
\mathbf{C}_{2} & 0 & 0 \\
0 & \mathbf{C}_{2} & 0 \\
0 & 0 & \mathbf{C}_{2}
\end{array}\right], \\
& \mathbf{K}_{\mathbf{d b}}^{\mathbf{g}}=0, \\
& \mathbf{K}_{\mathbf{b b}}^{\mathbf{g}}=0,
\end{aligned}
$$

where

$$
\begin{aligned}
\mathbf{C}_{1} & =\left[\begin{array}{llll}
p_{2,1}(0) & p_{2,2}(0) & \cdots & p_{2,2 M}(0) \\
p_{2,1}(1) & p_{2,2}(1) & \cdots & p_{2,2 M}(1)
\end{array}\right], \\
\mathbf{C}_{2} & =\left[\begin{array}{ll}
0 & 1 \\
1 & 1
\end{array}\right] .
\end{aligned}
$$

\section{Data Availability}

All data used to support the findings of this study are included within this published article. The source code that supports the findings of this study is available from the corresponding author upon reasonable request.

\section{Conflicts of Interest}

The authors declare that there are no potential conflicts of interest with respect to the research, authorship, and/or publication of this article.

\section{Acknowledgments}

This work was supported by the National Nature Science Foundation of China (Grant nos. 51575419 and 51705387), the 111 Project (Grant no. B14042), the Joint Funds of Education of China (Grant no. 6141A02022107), and the Fundamental Research Funds for the Central Universities (Grant no. SPSY101405).

\section{References}

[1] C. H. Sun, F. Li, H. M. Cheng, and G. Q. Lu, "Axial Young's modulus prediction of single-walled carbon nanotube arrays with diameters from nanometer to meter scales," Applied Physics Letters, vol. 87, no. 19, p. 193101, 2005.

[2] F. H. Gojny, M. H. G. Wichmann, B. Fiedler, and K. Schulte, "Influence of different carbon nanotubes on the mechanical properties of epoxy matrix composites-a comparative study," Composites Science and Technology, vol. 65, no. 15-16, pp. 2300-2313, 2005.
[3] M. Omidi, H. D. T. Rokni, A. S. Milani, R. J. Seethaler, and R. Arasteh, "Prediction of the mechanical characteristics of multi-walled carbon nanotube/epoxy composites using a new form of the rule of mixtures," Carbon, vol. 48, no. 11, pp. 3218-3228, 2010.

[4] H.-S. Shen, "Nonlinear bending of functionally graded carbon nanotube-reinforced composite plates in thermal environments," Composite Structures, vol. 91, no. 1, pp. 9-19, 2009.

[5] H. Kwon, C. R. Bradbury, and M. Leparoux, "Fabrication of functionally graded carbon nanotube-reinforced aluminum matrix composite," Advanced Engineering Materials, vol. 13, no. 4, pp. 325-329, 2011.

[6] S. H. Tagrara, A. Benachour, M. B. Bouiadjra, and A. Tounsi, "On bending, buckling and vibration responses of functionally graded carbon nanotube-reinforced composite beams," Steel and Composite Structures, vol. 19, no. 5, pp. 1259-1277, 2015.

[7] H. S. Shen, "Postbuckling of nanotube-reinforced composite cylindrical panels resting on elastic foundations subjected to lateral pressure in thermal environments," Engineering Structures, vol. 122, pp. 174-183, 2016.

[8] H.-S. Shen and Y. Xiang, "Postbuckling of nanotubereinforced composite cylindrical shells under combined axial and radial mechanical loads in thermal environment," Composites Part B: Engineering, vol. 52, pp. 311-322, 2013.

[9] L. W. Zhang, K. M. Liew, and J. N. Reddy, "Postbuckling of carbon nanotube reinforced functionally graded plates with edges elastically restrained against translation and rotation under axial compression," Computer Methods in Applied Mechanics and Engineering, vol. 298, pp. 1-28, 2016.

[10] M. Mirzaei and Y. Kiani, "Thermal buckling of temperature dependent FG-CNT reinforced composite conical shells," Aerospace Science and Technology, vol. 47, pp. 42-53, 2015.

[11] Z.-X. Wang and H.-S. Shen, "Nonlinear dynamic response of nanotube-reinforced composite plates resting on elastic foundations in thermal environments," Nonlinear Dynamics, vol. 70, no. 1, pp. 735-754, 2012.

[12] J. Y. Fan, J. Huang, J. B. Ding, and J. Zhang, "Free vibration of functionally graded carbon nanotube-reinforced conical panels integrated with piezoelectric layers subjected to elastically restrained boundary conditions," Advances in $\mathrm{Me}$ chanical Engineering, vol. 9, no. 7, 2017.

[13] H.-S. Shen and Y. Xiang, "Nonlinear vibration of nanotubereinforced composite cylindrical shells in thermal environments," Computer Methods in Applied Mechanics and Engineering, vol. 213-216, pp. 196-205, 2012.

[14] A. R. Setoodeh and M. Shojaee, "Application of TW-DQ, method to nonlinear free vibration analysis of FG carbon nanotube-reinforced composite quadrilateral plates," ThinWalled Structures, vol. 108, pp. 1-11, 2016.

[15] K. M. Liew, Z. X. Lei, and L. W. Zhang, "Mechanical analysis of functionally graded carbon nanotube reinforced composites: a review," Composite Structures, vol. 120, pp. 90-97, 2015.

[16] L.-L. Ke, J. Yang, and S. Kitipornchai, "Nonlinear free vibration of functionally graded carbon nanotube-reinforced composite beams," Composite Structures, vol. 92, no. 3, pp. 676-683, 2010.

[17] L.-L. Ke, J. Yang, and S. Kitipornchai, "Dynamic stability of functionally graded carbon nanotube-reinforced composite beams," Mechanics of Advanced Materials and Structures, vol. 20, no. 1, pp. 28-37, 2013.

[18] H. L. Wu, J. Yang, and S. Kitipornchai, "Nonlinear vibration of functionally graded carbon nanotube-reinforced composite 
beams with geometric imperfections," Composites Part B: Engineering, vol. 90, pp. 86-96, 2016.

[19] H. L. Wu, J. Yang, and S. Kitipornchai, "Imperfection sensitivity of postbuckling behaviour of functionally graded carbon nanotube-reinforced composite beams," Thin-Walled Structures, vol. 108, pp. 225-233, 2016.

[20] H. L. Wu, S. Kitipornchai, and J. Yang, "Imperfection sensitivity of thermal post-buckling behaviour of functionally graded carbon nanotube-reinforced composite beams," Applied Mathematical Modelling, vol. 42, pp. 735-752, 2017.

[21] R. Ansari, M. F. Shojaei, V. Mohammadi, R. Gholami, and F. Sadeghi, "Nonlinear forced vibration analysis of functionally graded carbon nanotube-reinforced composite Timoshenko beams," Composite Structures, vol. 113, pp. 316-327, 2014.

[22] H.-S. Shen and Y. Xiang, "Nonlinear analysis of nanotubereinforced composite beams resting on elastic foundations in thermal environments," Engineering Structures, vol. 56, pp. 698-708, 2013.

[23] M. H. Yas and N. Samadi, "Free vibrations and buckling analysis of carbon nanotube-reinforced composite Timoshenko beams on elastic foundation," International Journal of Pressure Vessels and Piping, vol. 98, pp. 119-128, 2012.

[24] H. Haddadpour, S. Mahmoudkhani, and H. M. Navazi, "Free vibration analysis of functionally graded cylindrical shells including thermal effects," Thin-Walled Structures, vol. 45, no. 6, pp. 591-599, 2007.

[25] E. Babolian and F. Fattahzadeh, "Numerical solution of differential equations by using Chebyshev wavelet operational matrix of integration," Applied Mathematics and Computation, vol. 188, no. 1, pp. 417-426, 2007.

[26] S. A. Yousefi, "Legendre wavelets method for solving differential equations of Lane-Emden type," Applied Mathematics and Computation, vol. 181, no. 2, pp. 1417-1422, 2006.

[27] A. I. Neelov and S. Goedecker, "An efficient numerical quadrature for the calculation of the potential energy of wavefunctions expressed in the Daubechies wavelet basis," Journal of Computational Physics, vol. 217, no. 2, pp. 312-339, 2006.

[28] U. Lepik, "Numerical solution of differential equations using Haar wavelets," Mathematics and Computers in Simulation, vol. 68, no. 2, pp. 127-143, 2005.

[29] U. Lepik and E. Tamme, "Solution of nonlinear Fredholm integral equations via the Haar wavelet method," Proceedings of the Estonian Academy of Sciences-Physics Mathematics, vol. 56, pp. 17-27, 2007.

[30] Z. Shi, Y.-h. Xu, and J.-p. Zhao, "Haar wavelets method for solving Poisson equations with jump conditions in irregular domain," Advances in Computational Mathematics, vol. 42, no. 4, pp. 995-1012, 2016.

[31] S. Arbabi, A. Nazari, and M. T. Darvishi, "A two-dimensional Haar wavelets method for solving systems of PDEs," Applied Mathematics and Computation, vol. 292, pp. 33-46, 2017.

[32] Siraj-ul-Islam, I. Aziz, and A. S. Al-Fhaid, "An improved method based on Haar wavelets for numerical solution of nonlinear integral and integro-differential equations of first and higher orders," Journal of Computational and Applied Mathematics, vol. 260, pp. 449-469, 2014.

[33] X. Xie, G. Y. Jin, W. Y. Li, and Z. G. Liu, "A numerical solution for vibration analysis of composite laminated conical, cylindrical shell and annular plate structures," Composite Structures, vol. 111, pp. 20-30, 2014.
[34] X. Xie, G. Jin, and Z. Liu, "Free vibration analysis of cylindrical shells using the Haar wavelet method," International Journal of Mechanical Sciences, vol. 77, pp. 47-56, 2013.

[35] H. Hein and L. Feklistova, "Free vibrations of non-uniform and axially functionally graded beams using Haar wavelets," Engineering Structures, vol. 33, no. 12, pp. 3696-3701, 2011.

[36] J. Majak, B. Shvartsman, K. Karjust, M. Mikola, A. Haavajoe, and M. Pohlak, "On the accuracy of the Haar wavelet discretization method," Composites Part B: Engineering, vol. 80, pp. 321-327, 2015.

[37] J. Majak, M. Pohlak, K. Karjust, M. Eerme, J. Kurnitski, and B. S. Shvartsman, "New higher order Haar wavelet method: application to FGM structures," Composite Structures, vol. 201, pp. 72-78, 2018.

[38] A. H. Sofiyev, "Large amplitude vibration of FGM orthotropic cylindrical shells interacting with the nonlinear Winkler elastic foundation," Composites Part B: Engineering, vol. 98, pp. 141-150, 2016.

[39] Z.-X. Wang and H.-S. Shen, "Nonlinear vibration of nanotube-reinforced composite plates in thermal environments," Computational Materials Science, vol. 50, no. 8, pp. 2319-2330, 2011.

[40] H. Wu, S. Kitipornchai, and J. Yang, "Thermo-electromechanical postbuckling of piezoelectric FG-CNTRC beams with geometric imperfections," Smart Materials and Structures, vol. 25, no. 9, article 095022, 2016.

[41] I. Singh and S. Kumar, "Haar wavelet method for some nonlinear Volterra integral equations of the first kind," Journal of Computational and Applied Mathematics, vol. 292, pp. 541-552, 2016.

[42] Z. Shi and Y. Cao, "Application of Haar wavelet method to eigenvalue problems of high order differential equations," Applied Mathematical Modelling, vol. 36, no. 9, pp. 40204026, 2012.

[43] M. Mirzaei and Y. Kiani, "Nonlinear free vibration of temperature-dependent sandwich beams with carbon nanotube-reinforced face sheets," Acta Mechanica, vol. 227, no. 7, pp. 1869-1884, 2016.

[44] J. Majak, B. S. Shvartsman, M. Kirs, M. Pohlak, and H. Herranen, "Convergence theorem for the Haar wavelet based discretization method," Composite Structures, vol. 126, pp. 227-232, 2015.

[45] F. Lin and Y. Xiang, "Numerical analysis on nonlinear free vibration of carbon nanotube reinforced composite beams," International Journal of Structural Stability and Dynamics, vol. 14, no. 1, article 1350056, 2014. 


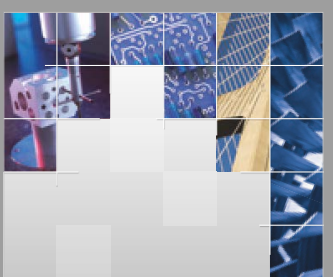

\section{Enfincering}
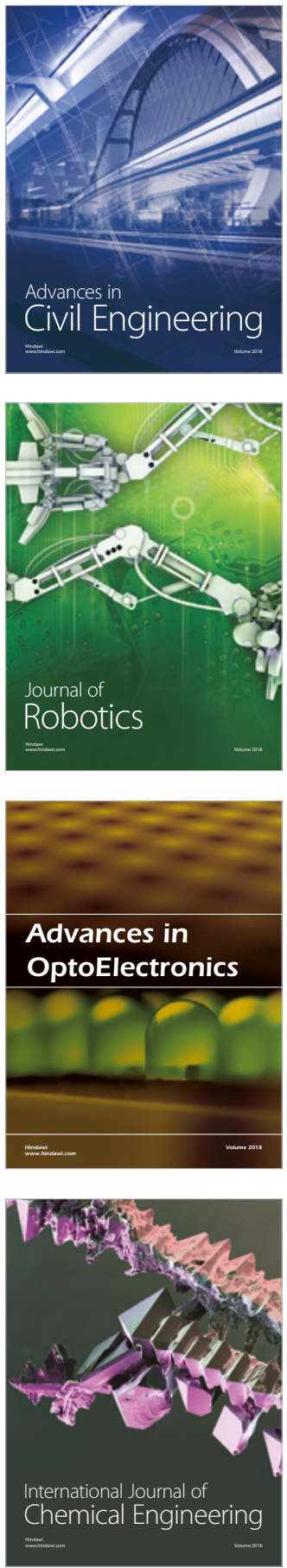

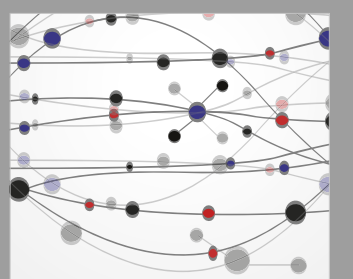

\section{Rotating \\ Machinery}

The Scientific World Journal

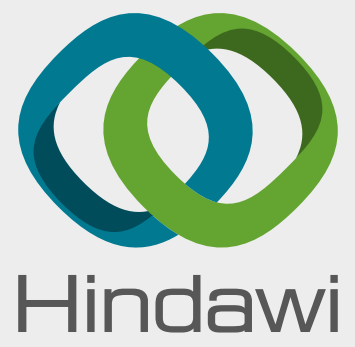

Submit your manuscripts at

www.hindawi.com
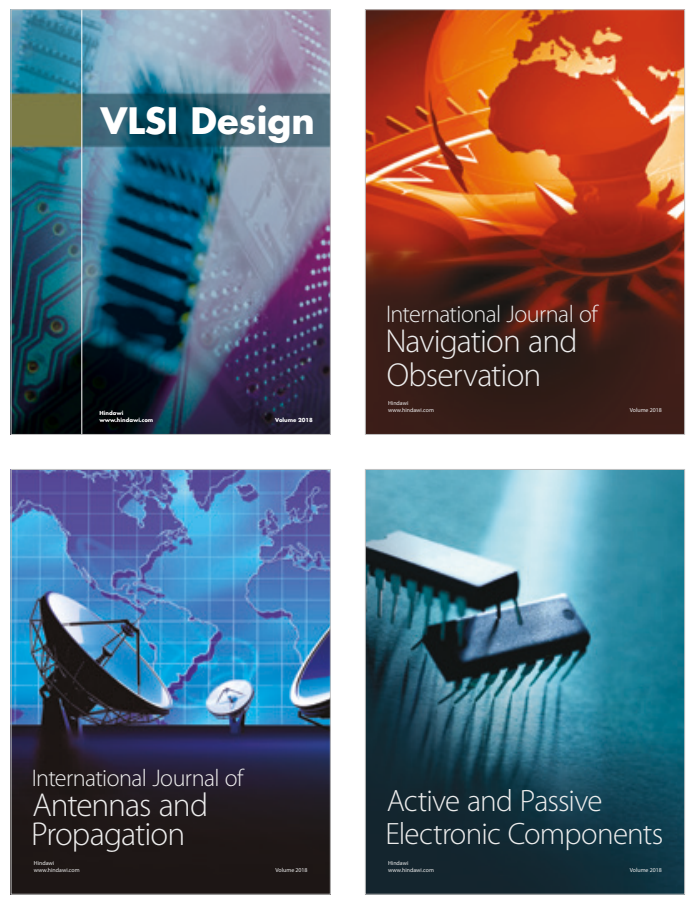
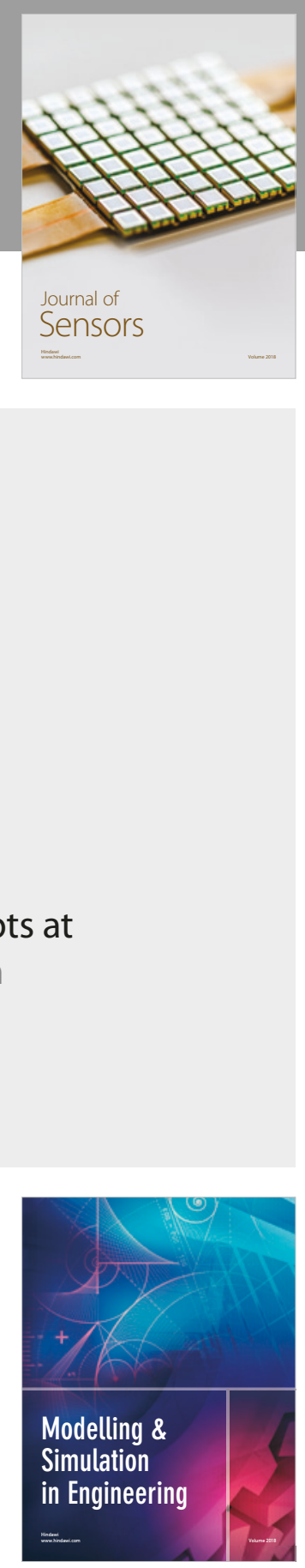

\section{Advances \\ Multimedia}
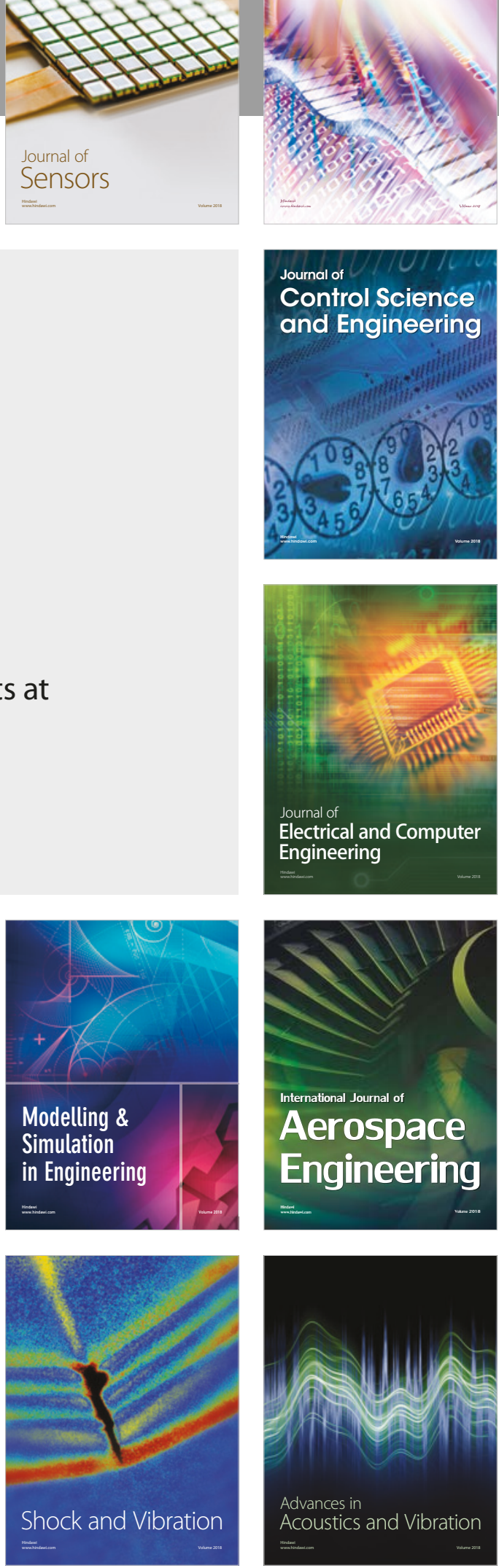